\title{
Accurate and precise quantification of atmospheric nitrate in streams draining land of various uses by using triple oxygen isotopes as tracers
}

\author{
Urumu Tsunogai $^{1}$, Takanori Miyauchi ${ }^{1}$, Takuya Ohyama ${ }^{1}$, Daisuke D. Komatsu ${ }^{1, a}$, Fumiko Nakagawa ${ }^{1}$, \\ Yusuke Obata ${ }^{2, b}$, Keiichi Sato ${ }^{3}$, and Tsuyoshi Ohizumi ${ }^{3, c}$ \\ ${ }^{1}$ Graduate School of Environmental Studies, Nagoya University, Furo-cho, Chikusa-ku, Nagoya 464-8601, Japan \\ ${ }^{2}$ Faculty of Bioresources, Mie University, 1577 Kurimamachiya-cho, Tsu 514-8507, Japan \\ ${ }^{3}$ Asia Center for Air Pollution Research, 1182 Sowa Nishi-ku, Niigata 950-2144, Japan \\ anow at: School of Marine Science and Technology, Tokai University, 3-20-1 Orito, Shimizu, Shizuoka 424-8610, Japan \\ ${ }^{b}$ now at: Graduate School of Environmental Studies, Nagoya University, Furo-cho, Chikusa-ku, Nagoya 464-8601, Japan \\ ${ }^{c}$ now at: Niigata Prefectural Institute of Public Health and Environmental Sciences, 314-1, Sowa, \\ Niigata, Niigata 950-2144, Japan
}

Correspondence to: Urumu Tsunogai (urumu@nagoya-u.jp)

Received: 7 December 2015 - Published in Biogeosciences Discuss.: 18 January 2016

Revised: 19 May 2016 - Accepted: 25 May 2016 - Published: 15 June 2016

\begin{abstract}
Land use in a catchment area has significant impacts on nitrate eluted from the catchment, including atmospheric nitrate deposited onto the catchment area and remineralised nitrate produced within the catchment area. Although the stable isotopic compositions of nitrate eluted from a catchment can be a useful tracer to quantify the land use influences on the sources and behaviour of the nitrate, it is best to determine these for the remineralised portion of the nitrate separately from the unprocessed atmospheric nitrate to obtain a more accurate and precise quantification of the land use influences. In this study, we determined the spatial distribution and seasonal variation of stable isotopic compositions of nitrate for more than 30 streams within the same watershed, the Lake Biwa watershed in Japan, in order to use ${ }^{17} \mathrm{O}$ excess $\left(\Delta^{17} \mathrm{O}\right)$ of nitrate as an additional tracer to quantify the mole fraction of atmospheric nitrate accurately and precisely. The stable isotopic compositions, including $\Delta^{17} \mathrm{O}$ of nitrate, in precipitation (wet deposition; $n=196$ ) sampled at the Sadoseki monitoring station were also determined for 3 years. The deposited nitrate showed large ${ }^{17} \mathrm{O}$ excesses similar to those already reported for midlatitudes: $\Delta^{17} \mathrm{O}$ values ranged from +18.6 to $+32.4 \%$ with a 3 -year average of $+26.3 \%$. However, nitrate in each inflow stream showed small annual average $\Delta^{17} \mathrm{O}$ values ranging from +0.5 to $+3.1 \%$, which cor-
\end{abstract}

responds to mole fractions of unprocessed atmospheric nitrate to total nitrate from $(1.8 \pm 0.3)$ to $(11.8 \pm 1.8) \%$ respectively, with an average for all inflow streams of $(5.1 \pm 0.5) \%$. Although the annual average $\Delta^{17} \mathrm{O}$ values tended to be smaller in accordance with the increase in annual average stream nitrate concentration from 12.7 to $106.2 \mu \mathrm{mol} \mathrm{L}-1$, the absolute concentrations of unprocessed atmospheric nitrate were almost stable at $(2.3 \pm 1.1) \mu \mathrm{mol} \mathrm{L} \mathrm{L}^{-1}$ irrespective of the changes in population density and land use in each catchment area. We conclude that changes in population density and land use between each catchment area had little impact on the concentration of atmospheric nitrate and that the total nitrate concentration originated primarily from additional contributions of remineralised nitrate. By using the average stable isotopic compositions of atmospheric nitrate, we excluded the contribution of atmospheric nitrate from the determined $\delta^{15} \mathrm{~N}$ and $\delta^{18} \mathrm{O}$ values of total nitrate and estimated the $\delta^{15} \mathrm{~N}$ and $\delta^{18} \mathrm{O}$ values of the remineralised portion of nitrate in each stream to clarify the sources. We found that the remineralised portion of the nitrate in the streams could be explained by mixing between a natural source with values of $(+4.4 \pm 1.8)$ and $(-2.3 \pm 0.9) \%$ for $\delta^{15} \mathrm{~N}$ and $\delta^{18} \mathrm{O}$ respectively and an anthropogenic source with values of $(+9.2 \pm 1.3)$ and $(-2.2 \pm 1.1) \%$ for $\delta^{15} \mathrm{~N}$ and $\delta^{18} \mathrm{O}$ respec- 
tively. In addition, both the uniform absolute concentration of atmospheric nitrate and the low and uniform $\delta^{18} \mathrm{O}$ values of the remineralised portion of nitrate in the streams imply that in-stream removal of nitrate through assimilation or denitrification had little impact on the concentrations and stable isotopic compositions of nitrate in the streams, except for a few streams in summer with catchments of urban/suburban land uses.

\section{Introduction}

Nitrate $\left(\mathrm{NO}_{3}^{-}\right)$in stream water can be an important source of information for understanding the biogeochemical cycles within the catchment area of the stream (Likens et al., 1970; Durka et al., 1994; Swank et al., 2001). In addition, the nitrate concentration in stream water is important to primary production, and an excess of nitrate can lead to eutrophication in downstream areas, including receiving lakes, estuaries, and oceans (McIsaac et al., 2001; Paerl, 2009). However, nitrate concentrations in stream water are determined through a complicated interplay of several processes within the catchment area including (1) the addition of atmospheric nitrate $\left(\mathrm{NO}_{3}^{-}(\mathrm{atm})\right)$ through deposition, (2) the production of remineralised nitrate $\left(\mathrm{NO}_{3}^{-}(\mathrm{re})\right)$ through microbial nitrification, (3) the removal of nitrate through assimilation by plants and microbes, and (4) the removal of nitrate through denitrification by microbes. In addition to natural processes, anthropogenic processes can have a significant impact on the sources and dynamics of nitrate within each catchment area, particularly those with urban or agricultural catchment zones. Therefore, interpretation of the processes regulating nitrate concentration in stream water is not always straightforward.

The ${ }^{15} \mathrm{~N} /{ }^{14} \mathrm{~N}$ and ${ }^{18} \mathrm{O} /{ }^{16} \mathrm{O}$ ratios of nitrate have been widely applied worldwide in the determination of the sources and behaviours of nitrate in stream water (Durka et al., 1994; Campbell et al., 2002; Silva et al., 2002; Barnes and Raymond, 2010; Nestler et al., 2011; Lohse et al., 2013). By combining the two isotopic ratios, the relative mole fractions among various nitrate sources such as atmospheric (unprocessed), fertiliser, manure, and sewage plants can be quantified through a simple isotope mass balance approach. Partial removal of nitrate through either assimilation or denitrification, however, results in residual nitrate being enriched with ${ }^{15} \mathrm{~N}$ and ${ }^{18} \mathrm{O}$ (Böttcher et al., 1990; Granger et al., 2010), which complicates the interpretation of the ratios beyond that of the simple isotope mass balance approach. In addition, trace contributions of unprocessed $\mathrm{NO}_{3}^{-}(\mathrm{atm})$ can have a significant impact on the ${ }^{18} \mathrm{O} /{ }^{16} \mathrm{O}$ ratios of the total nitrate in stream water (Durka et al., 1994; Kendall, 1998; Mayer et al., 2001; Michalski et al., 2004; Tsunogai et al., 2010). Therefore, ${ }^{18} \mathrm{O} /{ }^{16} \mathrm{O}$ ratios are used as tracers based on assumptions such as (1) the ${ }^{18} \mathrm{O} /{ }^{16} \mathrm{O}$ ratios of nitrate in stream water simply reflect the mole fraction of unprocessed $\mathrm{NO}_{3}^{-}(\mathrm{atm})$ within total nitrate (Durka et al., 1994; Williard et al., 2001; Ohte et al., 2004; Campbell et al., 2006; Barnes et al., 2008; Burns et al., 2009; Ohte et al., 2010; Tobari et al., 2010; Thibodeau et al., 2013; Zeng and $\mathrm{Wu}, 2015)$, (2) the mole fractions of unprocessed $\mathrm{NO}_{3}^{-}(\mathrm{atm})$ within total nitrate are minimum for specific samples (such as soil solution samples) studied (Hales et al., 2007), and (3) the mole fractions of unprocessed $\mathrm{NO}_{3}^{-}(\mathrm{atm})$ within total nitrate are uniform in the entire samples studied (Wankel et al., 2006; Johannsen et al., 2008). To verify the reliability of these assumptions and to utilise the ${ }^{18} \mathrm{O} /{ }^{16} \mathrm{O}$ ratios for quantification of the mole fractions among various nitrate sources based on the isotope mass balance approach, the mole fraction of $\mathrm{NO}_{3}^{-}(\mathrm{atm})$ within the total nitrate in stream water must be better understood based on more accurate and more precise quantification rather than on traditional quantification using the ${ }^{15} \mathrm{~N} /{ }^{14} \mathrm{~N}$ and ${ }^{18} \mathrm{O} /{ }^{16} \mathrm{O}$ ratios of nitrate.

To overcome the limitation in using the ${ }^{15} \mathrm{~N} /{ }^{14} \mathrm{~N}$ and ${ }^{18} \mathrm{O} /{ }^{16} \mathrm{O}$ ratios, the ${ }^{17} \mathrm{O} /{ }^{16} \mathrm{O}$ ratios of nitrate have been used as an additional tracer of $\mathrm{NO}_{3}^{-}(\mathrm{atm})$ in stream water in recent studies (Michalski et al., 2004; Tsunogai et al., 2010; Costa et al., 2011; Dejwakh et al., 2012; Riha et al., 2014; Tsunogai et al., 2014; Rose et al., 2015). Because the oxygen atoms of $\mathrm{NO}_{3}^{-}(\mathrm{re})$ are derived from either terrestrial $\mathrm{O}_{2}$ or $\mathrm{H}_{2} \mathrm{O}$ through usual chemical reactions such as nitrification, $\mathrm{NO}_{3}^{-}(\mathrm{re})$ shows mass-dependent relative variations between ${ }^{17} \mathrm{O} /{ }^{16} \mathrm{O}$ and ${ }^{18} \mathrm{O} /{ }^{16} \mathrm{O}$ ratios. However, only unprocessed $\mathrm{NO}_{3}^{-}(\mathrm{atm})$ displays an anomalous enrichment in ${ }^{17} \mathrm{O}$ from the mass-dependent relative variations, reflecting oxygen atom transfers from ozone anomalously enriched in ${ }^{17} \mathrm{O}$ during the conversion of $\mathrm{NO}_{x}$ to $\mathrm{NO}_{3}^{-}(\mathrm{atm})$ (Michalski et al., 2003; Morin et al., 2008). By using the $\Delta^{17} \mathrm{O}$ signature (the magnitude of ${ }^{17} \mathrm{O}$ excess) defined by the following equation (Miller, 2002; Kaiser et al., 2007), we can distinguish unprocessed $\mathrm{NO}_{3}^{-}(\mathrm{atm})\left(\Delta^{17} \mathrm{O}>0\right)$ from $\mathrm{NO}_{3}^{-}(\mathrm{re})\left(\Delta^{17} \mathrm{O}=0\right)$ :

$\Delta^{17} \mathrm{O}=\frac{1+\delta^{17} \mathrm{O}}{\left(1+\delta^{18} \mathrm{O}\right)^{\beta}}-1$,

where the constant $\beta$ is 0.5279 (Miller, 2002; Kaiser et al., 2007), $\delta^{18} \mathrm{O}=R_{\text {sample }} / R_{\text {standard }}-1$, and $R$ is the ${ }^{18} \mathrm{O} /{ }^{16} \mathrm{O}$ ratio of the sample (or the ${ }^{17} \mathrm{O} /{ }^{16} \mathrm{O}$ ratio in the case of $\delta^{17} \mathrm{O}$ or the ${ }^{15} \mathrm{~N} /{ }^{14} \mathrm{~N}$ ratio in the case of $\delta^{15} \mathrm{~N}$ ) and each standard reference material. Please note that all the nitrate other than the unprocessed $\mathrm{NO}_{3}^{-}(\mathrm{atm})$ is classified into $\mathrm{NO}_{3}^{-}(\mathrm{re})$, including the nitrate produced through natural/anthropogenic processes in the biosphere/hydrosphere/geosphere and that stored in soil, fertiliser, manure, sewage, etc.

In addition, $\Delta^{17} \mathrm{O}$ is stable during the mass-dependent isotope fractionation processes within surface ecosystems. Therefore, although the atmospheric $\delta^{15} \mathrm{~N}$ or $\delta^{18} \mathrm{O}$ signature can be overprinted by biogeochemical processes subsequent to deposition, $\Delta{ }^{17} \mathrm{O}$ can be used as a robust tracer of unprocessed $\mathrm{NO}_{3}^{-}(\mathrm{atm})$ to reflect the accurate mole fraction of un- 


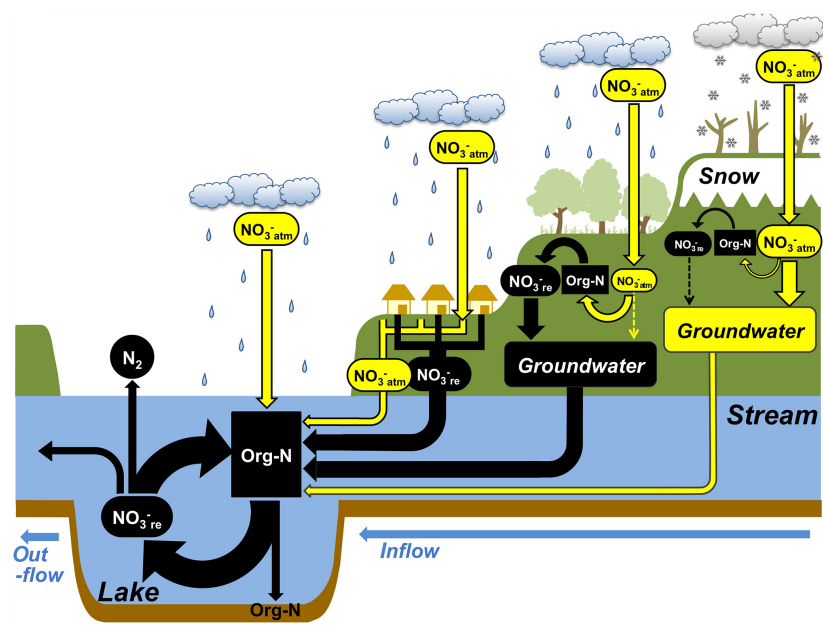

Figure 1. Schematic diagram showing the biological processing of atmospheric nitrate $\left(\mathrm{NO}_{3}^{-}(\mathrm{atm})\right)$ and remineralised nitrate $\left(\mathrm{NO}_{3}^{-}(\mathrm{re})\right)$ in the watershed with catchments of various land uses and in the lake water column.

processed $\mathrm{NO}_{3}^{-}$(atm) within total $\mathrm{NO}_{3}^{-}$regardless of biogeochemical partial removal processes subsequent to deposition by using the following equation:

$\frac{C_{\text {atm }}}{C_{\text {total }}}=\frac{\Delta^{17} \mathrm{O}}{\Delta^{17} \mathrm{O}_{\mathrm{atm}}}$,

where $C_{\text {atm }}$ and $C_{\text {total }}$ denote the concentrations of $\mathrm{NO}_{3}^{-}$(atm) and $\mathrm{NO}_{3}^{-}$in each water sample respectively, and $\Delta^{17} \mathrm{O}_{\text {atm }}$ and $\Delta^{17} \mathrm{O}$ denote the $\Delta^{17} \mathrm{O}$ values of $\mathrm{NO}_{3}^{-}($atm $)$and nitrate (total) in each water sample respectively. This is the primary merit of using the ${ }^{17} \mathrm{O} /{ }^{16} \mathrm{O}$ ratio as an additional tracer of $\mathrm{NO}_{3}^{-}(\mathrm{atm})$.

Moreover, additional measurements of the $\Delta^{17} \mathrm{O}$ values of nitrate together with $\delta^{15} \mathrm{~N}$ and $\delta^{18} \mathrm{O}$ enable us to exclude the contribution of $\mathrm{NO}_{3}^{-}(\mathrm{atm})$ in the determined $\delta^{15} \mathrm{~N}$ and $\delta^{18} \mathrm{O}$ values and to estimate the corrected $\delta^{15} \mathrm{~N}$ and $\delta^{18} \mathrm{O}$ values $\left(\delta^{15} \mathrm{~N}_{\mathrm{re}}\right.$ and $\delta^{18} \mathrm{O}_{\mathrm{re}}$ respectively) for accurate evaluation of the source and behaviour of $\mathrm{NO}_{3}^{-}$(re) (Tsunogai et al., 2010, 2011, 2014; Dejwakh et al., 2012; Liu et al., 2013; Riha et al., 2014), including $\mathrm{NO}_{3}^{-}$(re) produced through anthropogenic processes. The details of the calculation are presented in Sec. 2.5.

Previous studies have successfully applied the $\Delta^{17} \mathrm{O}$ tracer to nitrate eluted from arid/semi-arid watersheds (Michalski et al., 2004; Dejwakh et al., 2012; Riha et al., 2014), forested watersheds (Tsunogai et al., 2010, 2014; Rose et al., 2015), and a large river basin (Liu et al., 2013) to determine mole fractions of unprocessed $\mathrm{NO}_{3}^{-}(\mathrm{atm})$ in total nitrate more accurately and precisely than ever before, in addition to the fate of the $\mathrm{NO}_{3}^{-}(\mathrm{atm})$ that had been deposited into each watershed. However, relative changes in the fate of $\mathrm{NO}_{3}^{-}(\mathrm{atm})$ in accordance with the changes in land use of catchments have not been studied thus far by using the $\Delta^{17} \mathrm{O}$ tracer of nitrate.
In this study, we measured the concentrations and the stable isotopic compositions of nitrate including $\Delta^{17} \mathrm{O}$ values for more than 30 streams flowing into a lake in Japan with catchments of widely varying land uses, which includes urban, suburban, agricultural (mostly rice paddies), and forested catchments. By using the $\Delta^{17} \mathrm{O}$ tracer, we quantified both spatial and temporal variations in the concentrations of both $\mathrm{NO}_{3}^{-}(\mathrm{atm})$ and $\mathrm{NO}_{3}^{-}(\mathrm{re})$ in streams across the land use settings accurately and precisely to gain insight into the processes controlling the sources, transport, and fate of $\mathrm{NO}_{3}^{-}(\mathrm{atm})$ and $\mathrm{NO}_{3}^{-}$(re) (Fig. 1). Although $\mathrm{NO}_{3}^{-}$(re) increases during nitrification within each catchment area, $\mathrm{NO}_{3}^{-}(\mathrm{atm})$ is stable during nitrification, so we were able to evaluate the progress of nitrification within each catchment area by using the changes in the concentrations of both $\mathrm{NO}_{3}^{-}(\mathrm{atm})$ and $\mathrm{NO}_{3}^{-}(\mathrm{re})$. In addition to those from the streams, we determined the stable isotopic compositions of nitrate including $\Delta^{17} \mathrm{O}$ values in precipitation (wet deposition) for comparison to obtain accurate and precise mole fractions of both $\mathrm{NO}_{3}^{-}(\mathrm{atm})$ and $\mathrm{NO}_{3}^{-}(\mathrm{re})$ within nitrate (total) in each stream. Moreover, by using both the estimated mole fractions of $\mathrm{NO}_{3}^{-}(\mathrm{atm})$ in nitrate (total) and the $\delta^{15} \mathrm{~N}$ and $\delta^{18} \mathrm{O}$ values of $\mathrm{NO}_{3}^{-}(\mathrm{atm})$, we estimated the $\delta^{15} \mathrm{~N}_{\mathrm{re}}$ and $\delta^{18} \mathrm{O}_{\mathrm{re}}$ values for accurate evaluation of the source and behaviour of $\mathrm{NO}_{3}^{-}(\mathrm{re})$ in streams. Furthermore, we determined the concentrations and the stable isotopic compositions of nitrate including $\Delta^{17} \mathrm{O}$ values in an outflow river of the same lake to evaluate the influences of flow stagnation in the lake on the concentrations of both $\mathrm{NO}_{3}^{-}(\mathrm{atm})$ and $\mathrm{NO}_{3}^{-}(\mathrm{re})$ by using the differences between inflows and outflows (Fig. 1). The results presented herein increase our understanding of the fate of $\mathrm{NO}_{3}^{-}(\mathrm{atm})$ deposited onto land, particularly the fate of that deposited on urban/suburban and forested catchments (Fig. 1).

\section{Experimental section}

\subsection{Steam water samples}

Lake Biwa, located in the central part of the Japanese islands, is the largest freshwater lake in Japan (Fig. 2). It has a surface area of $670.4 \mathrm{~km}^{2}$, a total catchment area of $3174 \mathrm{~km}^{2}$, and annual precipitation of around $2000 \mathrm{~mm}$. More than 120 streams flow into the lake, but the Seta River (no. 33 in Fig. 2b) at the southern end of the lake, also known as the Yodo River, is the only natural outflow. The average residence time of water in the lake is 5.5 years.

Similar to many lakes throughout the world, Lake Biwa has experienced eutrophication in the past. Urbanisation near the lake, beginning in the 1960s, particularly on the southern and eastern shores, likely caused an increase in nutrient loading. Blooms of Uroglena americana and cyanobacteria have occurred since 1977 and 1983 respectively (Hsieh et al., 2011). To clarify the pathways and sources of nitrate that 
Table 1. List of studied streams.

\begin{tabular}{|c|c|c|c|c|c|c|c|c|c|c|c|}
\hline No. & Name & Loc. $^{\mathrm{a}}$ & $\begin{array}{r}\text { Basin area } \\
\left(\mathrm{km}^{2}\right)\end{array}$ & $\begin{array}{l}\text { Population density } \\
\qquad\left(\mathrm{km}^{-2}\right)\end{array}$ & Land use $e^{c}$ & No. & Name & Loc. $^{\mathrm{a}}$ & $\begin{array}{r}\text { Basin area } \\
\left(\mathrm{km}^{2}\right)\end{array}$ & $\begin{array}{l}\text { Population density } \\
\qquad\left(\mathrm{km}^{-2}\right)\end{array}$ & Land use $\mathrm{c}^{\mathrm{c}}$ \\
\hline \multicolumn{12}{|c|}{ Inflow } \\
\hline 31 & Tenjin & West & 10 & 539 & Forest & 14 & Seri & East & 74 & 462 & Forest \\
\hline 30 & Mano & West & 23 & 1048 & Forest & 15 & Inukami & East & 102 & 109 & Forest \\
\hline 29 & Wani & West & 17 & 186 & Forest & 16 & Ajiki & East & 15 & 1002 & Agr \\
\hline 28 & $\mathrm{U}$ & West & 7 & 66 & Forest & 17 & Uso & East & 84 & 411 & Agr \\
\hline 1 & Kamo & West & 47 & 89 & Forest & 18 & Bunroku & East & 14 & 595 & Agr \\
\hline 2 & Ado & West & 306 & 27 & Forest & 19 & Nomazu & East & 7 & 758 & Agr \\
\hline 3 & Ishida & North & 60 & 84 & Forest & 20 & Echi & East & 211 & 110 & Forest \\
\hline 4 & Momose & North & 13 & 65 & Forest & 27 & Hino & South & 226 & 338 & Forest \\
\hline 5 & Chinai & North & 51 & 44 & Forest & 26 & Yanomune & South & 42 & 859 & Agr \\
\hline 6 & Ohura & North & 39 & 98 & Forest & 25 & Yasu & South & 391 & 324 & Forest \\
\hline 7 & $\mathrm{Oh}$ & North & 20 & 55 & Forest & 24 & Yamaga & South & 6 & 2540 & Agr \\
\hline 8 & Yogo & North & 7 & 141 & Forest & 23 & Sakai & South & 2 & 979 & $\mathrm{Agr}$ \\
\hline 9 & Chonoki & North & 10 & 412 & Agr & 22 & Hayama & South & 34 & 2048 & Agr \\
\hline 10 & $\mathrm{Ta}$ & North & 36 & 301 & Agr & 34 & Kusatsu & South & 48 & 370 & Agr \\
\hline 11 & Ane & North & 372 & 61 & Forest & 21 & Nagaso & South & 4 & 3174 & Res \\
\hline 12 & Yone & North & 15 & 2047 & Agr & 32 & Fujinoki & South & 4 & 1805 & Forest \\
\hline 13 & Amano & North & 111 & 226 & Forest & & & & & & \\
\hline \multicolumn{12}{|c|}{ Outflow } \\
\hline 33 & Seta & South & 3848 & 323 & Forest & & & & & & \\
\hline
\end{tabular}

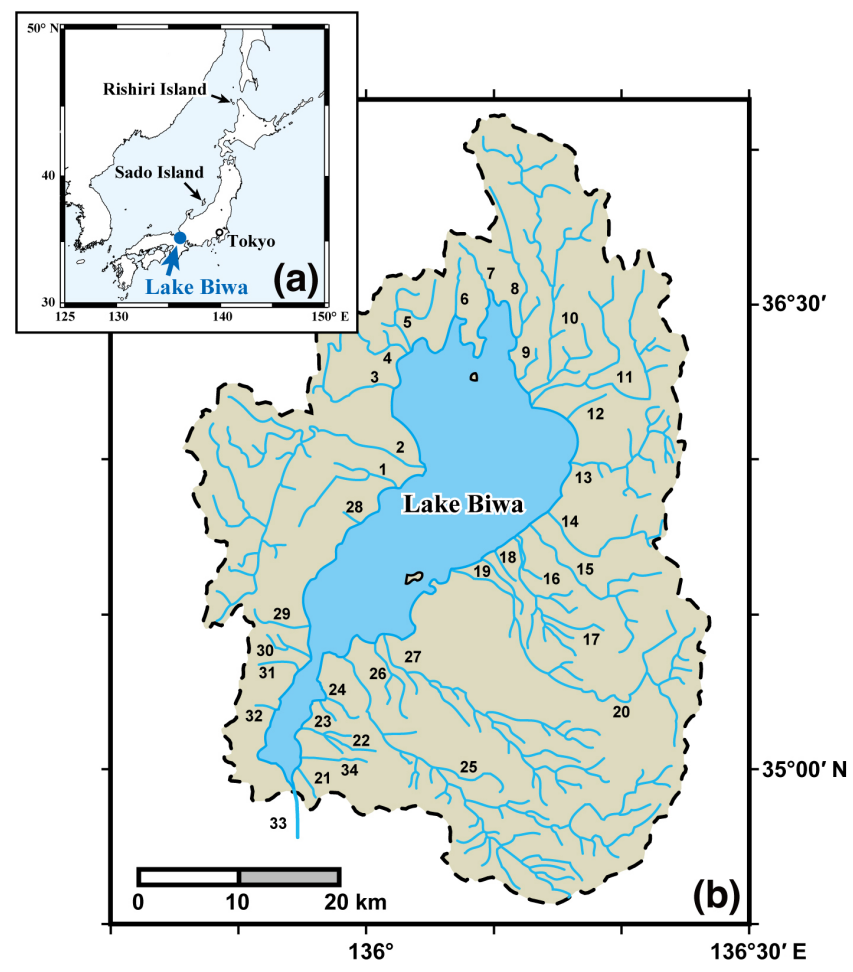

Figure 2. (a) Map showing the location of the Lake Biwa watershed basin in Japan and Sado Island, where the Sado-seki National Acid Rain Monitoring Station is located. (b) Map showing the boundary of the Lake Biwa watershed basin (dashed line) and the locations of the inflows (represented by numbers) and the outflow (Seta River, no. 33) studied in this paper (modified from Ohte et al., 2010). were fed into the lake, the stable isotopic compositions $\left(\delta^{15} \mathrm{~N}\right.$ and $\left.\delta^{18} \mathrm{O}\right)$ of dissolved nitrate were determined in the major streams flowing into the lake (Ohte et al., 2010). Based on the $\delta^{15} \mathrm{~N}$ values of nitrate showing positive correlation with the population densities of each catchment area, it was concluded that sewage effluent was the dominant source contributing to the increase in the $\delta^{15} \mathrm{~N}$ values of nitrate.

In this study, stream water samples were collected near the mouths of 33 inflow streams and 1 outflow river (Seta River) of Lake Biwa (Table 1; Fig. 2b) during base flow periods four times in 2013: on 15 March, 17 June, 5 August, and 21 October, except for stream nos. 3 and 28 in June, which became dry arroyos at that time. The catchments of the studied inflow streams occupied $70 \%$ of the entire Lake Biwa basin area. The streams were selected to cover those in which the concentrations and stable isotope compositions of nitrate, $\delta^{15} \mathrm{~N}$ and $\delta^{18} \mathrm{O}$, had already been determined in 2004-2006 (Ohte et al., 2010). The categories of locations classified by Ohte et al. (2010) were also used in this study to classify the location of each stream (Table 1). Either a bucket or dipper was used to collect samples as far from the bank as possible. Each sample was transferred into a dark polyethylene bottle that was pre-rinsed at least twice with the sample itself and subsequently stored in a refrigerator. Then, the samples were filtered through a pre-combusted Whatman GF/F filter with a $0.7 \mu \mathrm{m}$ pore size within a few hours after collection, and the filtrate was stored in a different dark polyethylene bottle at $4{ }^{\circ} \mathrm{C}$ until analysis.

In this study, we defined the sampling number $n$, where $n=1,2,3$, and 4, which represent the sampling in March, June, August, and October respectively. In addition, we de- 
fined one more hypothetical sampling number $(n=5)$ set just 1 year later than the $n=1$ date. Please note that there are no data for sampling $n=5$. Furthermore, we rated the intervals between $n=1$ and $n=2, n=2$ and $n=3, n=3$ and $n=4$, and $n=4$ and $n=5$ as spring, summer, autumn, and winter respectively for the streams in this study.

\subsection{Wet deposition samples}

The Sado-seki National Acid Rain Monitoring Station $\left(38^{\circ} 14^{\prime} 59^{\prime \prime} \mathrm{N}, 138^{\circ} 24^{\prime} 00^{\prime \prime} \mathrm{E}\right)$ was established on Sado Island (Fig. 2a), at $110 \mathrm{~m}$ above sea level, as a monitoring observatory of the Acid Deposition Monitoring Network in East Asia (EANET) representing the central Japan area (EANET, 2014). Samples of wet deposition were taken at the station by using standard methods for evaluating acid deposition in Japan for the 3 Japanese financial years (FYs) from April 2009 to March 2012. An automatic wet deposition sampler (US-420, Ogasawara) was used in the collection. All of the deposition samples were stored in $1 \mathrm{~L}$ polyethylene bottles under refrigeration until daily recovery. After measuring the volume (i.e. precipitation rate), conductivity, and $\mathrm{pH}$, the recovered samples were filtered through a $0.2 \mu \mathrm{m}$ pore-size membrane filter (Dismic-25CS, ADVANTEC) and stored in a refrigerator until analysis.

The annual wet deposition rate of nitrate was $19.3 \mathrm{mmol} \mathrm{m}^{-2} \mathrm{yr}^{-1}$ for FY2009, from April 2009 to March 2010; $28.0 \mathrm{mmol} \mathrm{m}^{-2} \mathrm{yr}^{-1}$ for FY2010, from April 2010 to March 2011; $27.0 \mathrm{mmol} \mathrm{m}^{-2} \mathrm{yr}^{-1}$ for FY2011, from April 2011 to March 2012; and $24.5 \mathrm{mmol} \mathrm{m}^{-2} \mathrm{yr}^{-1}$ on average from FY2009 to 2011 (EANET, 2014). The annual wet deposition rate of $\mathrm{NH}_{4}^{+}$was $17.1 \mathrm{mmol} \mathrm{m}^{-2} \mathrm{yr}^{-1}$ on average from FY2009 to 2011 (EANET, 2014).

\subsection{Analysis}

The concentrations of nitrate $\left(\mathrm{NO}_{3}^{-}\right)$and nitrite $\left(\mathrm{NO}_{2}^{-}\right)$in each filtrate sample were measured by ion chromatography (Prominence HIC-SP, Shimadzu, Japan) within a few days (stream water samples) and within 2 weeks (wet deposition samples) after each sampling. The error (standard error of the mean) in the determined concentrations of nitrate was $\pm 3 \%$. The $\delta^{18} \mathrm{O}$ values of $\mathrm{H}_{2} \mathrm{O}$ in the samples were analysed using the cavity ring-down spectroscopy method by employing an L2120-i instrument (Picarro Inc., Santa Clara, CA, USA) equipped with an A0211 vaporiser and auto sampler; the error (standard error of the mean) in this method was $\pm 0.1 \%$. Both Vienna Standard Mean Ocean Water (VSMOW) and Standard Light Antarctic Precipitation (SLAP) were used to calibrate the values to the international scale.

To determine the stable isotopic compositions, nitrate in each filtrate sample was chemically converted to $\mathrm{N}_{2} \mathrm{O}$ by using a method originally developed to determine the ${ }^{15} \mathrm{~N} /{ }^{14} \mathrm{~N}$ and ${ }^{18} \mathrm{O} /{ }^{16} \mathrm{O}$ ratios of seawater and freshwater nitrate $\mathrm{McIl}-$ vin and Altabet, 2005) and that was later modified (Tsunogai et al., 2008; Konno et al., 2010; Yamazaki et al., 2011). In brief, the procedures were as follows. Approximately $10 \mathrm{~mL}$ of each sample solution was pipetted into a vial with a septum cap. Then, $0.5 \mathrm{~g}$ of spongy cadmium was added, followed by $150 \mu \mathrm{L}$ of a $1 \mathrm{M} \mathrm{NaHCO}$ solution. The sample

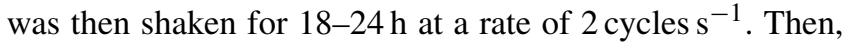
the sample solution was decanted into a different vial with a septum cap. After purging the solution using high purity helium, $0.4 \mathrm{~mL}$ of the azide/acetic acid buffer was added. After $45 \mathrm{~min}$, the solution was made basic by adding $0.2 \mathrm{~mL}$ of $6 \mathrm{M} \mathrm{NaOH}$.

Then, the stable isotopic compositions $\left(\delta^{15} \mathrm{~N}, \delta^{18} \mathrm{O}\right.$, and $\Delta^{17} \mathrm{O}$ ) of $\mathrm{N}_{2} \mathrm{O}$ in each vial were determined by using a continuous-flow isotope ratio mass spectrometry (CF-IRMS) system at Nagoya University. The analytical procedures using the CF-IRMS system were the same as those detailed in previous research (Komatsu et al., 2008; Hirota et al., 2010). The obtained values of $\delta^{15} \mathrm{~N}, \delta^{18} \mathrm{O}$, and $\Delta^{17} \mathrm{O}$ for $\mathrm{N}_{2} \mathrm{O}$ derived from the nitrate in each sample were compared with those derived from our local laboratory nitrate standards that had been calibrated using the internationally distributed isotope reference materials to calibrate the values of the sample nitrate to an international scale and to correct for both the isotope fractionation during the chemical conversion to $\mathrm{N}_{2} \mathrm{O}$ and the progress of oxygen isotope exchange between the nitrate-derived reaction intermediate and water (ca. $20 \%$ ). In this study, we adopted the internal standard method (Nakagawa et al., 2013; Tsunogai et al., 2014) for the calibrations of sample nitrate. All values in this paper are expressed relative to air (for nitrogen) and VSMOW (for oxygen).

To determine whether samples were deteriorated or contaminated during storage and whether the conversion rate from nitrate to $\mathrm{N}_{2} \mathrm{O}$ was sufficient, concentrations of nitrate in the samples were determined each time we analysed isotopic compositions using CF-IRMS based on the $\mathrm{N}_{2} \mathrm{O}^{+}$or $\mathrm{O}_{2}^{+}$outputs. We adopted the $\delta^{15} \mathrm{~N}, \delta^{18} \mathrm{O}$, or $\Delta^{17} \mathrm{O}$ values only when concentrations measured by CF-IRMS correlated with those measured by ion chromatography just after the sampling within a difference of $10 \%$. About $10 \%$ of the whole isotope analyses showed conversion efficiencies lower than this criterion. Nitrate in these samples was converted to $\mathrm{N}_{2} \mathrm{O}$ again and re-analysed for the stable isotopic compositions. None of the samples showed significant nitrate deterioration or nitrate contamination during storage.

We repeated the analyses of the $\delta^{15} \mathrm{~N}, \delta^{18} \mathrm{O}$, and $\Delta^{17} \mathrm{O}$ values of nitrate for each sample at least three times to attain high precision. Most of the samples had a nitrate concentration of more than $5.0 \mu \mathrm{mol} \mathrm{L}{ }^{-1}$, which corresponded to a nitrate quantity greater than $50 \mathrm{nmol}$ in a $10 \mathrm{~mL}$ sample. This amount was sufficient for determining the $\delta^{15} \mathrm{~N}, \delta^{18} \mathrm{O}$, and $\Delta^{17} \mathrm{O}$ values with high precision. For cases of nitrate concentration less than $5.0 \mu \mathrm{mol} \mathrm{L}{ }^{-1}$, the sample volume was increased to $30 \mathrm{~mL}$ and the number of analyses was also increased. Thus, all isotopic data presented in this study have 
an error (standard error of the mean) better than $\pm 0.2 \%$ for $\delta^{15} \mathrm{~N}, \pm 0.3 \%$ for $\delta^{18} \mathrm{O}$, and $\pm 0.1 \%$ or $\Delta^{17} \mathrm{O}$.

Nitrite $\left(\mathrm{NO}_{2}^{-}\right)$in the samples interferes with the final $\mathrm{N}_{2} \mathrm{O}$ produced from nitrate $\left(\mathrm{NO}_{3}^{-}\right)$because the chemical method also converts $\mathrm{NO}_{2}^{-}$to $\mathrm{N}_{2} \mathrm{O}$ (McIlvin and Altabet, 2005). Therefore, it is sometimes necessary to correct for the contribution of $\mathrm{NO}_{2}^{-}$-derived $\mathrm{N}_{2} \mathrm{O}$ to determine the stable isotopic compositions of the sample nitrate accurately. However, in this study, more than $90 \%$ of the samples analysed for stable isotopic compositions had $\mathrm{NO}_{2}^{-}$concentrations lower than the detection limit $\left(0.05 \mu \mathrm{mol} \mathrm{L}^{-1}\right)$. Even for the samples with $\mathrm{NO}_{2}^{-}$concentrations higher than the detection limit, the $\mathrm{NO}_{2}^{-} / \mathrm{NO}_{3}^{-}$ratio was less than $1 \%$. Thus, in this study, the results were used with no correction.

\subsection{Calculating average concentration and isotopic compositions in each stream}

To clarify the chemical and isotopic characteristics of each stream, we determined both the flow-weighted annual average concentration $\left(\bar{C}_{\text {total }}\right)$ and the flow-weighted annual average $\delta^{15} \mathrm{~N}, \delta^{18} \mathrm{O}$, and $\Delta^{17} \mathrm{O}$ values $(\bar{\delta})$ of nitrate for each stream assuming the same flow rate, the same nitrate concentration, and the same isotopic compositions for the interval until the next observation by using Eqs. (3), (4), and (5):

$$
\begin{aligned}
q & =\sum_{n=1}^{4}\left(f_{n} \cdot \Delta t_{n}\right), \\
\bar{C}_{\text {total }} & =\frac{\sum_{n=1}^{4}\left(C_{n} \cdot f_{n} \cdot \Delta t_{n}\right)}{q}, \\
\bar{\delta} & =\frac{\sum_{n=1}^{4}\left(\delta_{n} \cdot C_{n} \cdot f_{n} \cdot \Delta t_{n}\right)}{\sum_{n=1}^{4}\left(C_{n} \cdot f_{n} \cdot \Delta t_{n}\right)},
\end{aligned}
$$

where $C_{n}$ and $\delta_{n}$ denote the concentration ( $C_{\text {total }}$ in Eq. 2 ) and isotopic values $\left(\delta^{15} \mathrm{~N}, \delta^{18} \mathrm{O}\right.$, or $\left.\Delta^{17} \mathrm{O}\right)$ of nitrate in each stream during each observation $n$ respectively; $f_{n}$ denotes the flow rate of each stream during each observation $n$; and $\Delta t_{n}$ denotes the time interval between the observation $n$ and the next observation $n+1$. When possible, we used the flow rate of each stream that was determined monthly by the Shiga Prefecture (Shiga Prefecture, 2015) for $f_{n}$. For small streams with no data for flow rate $(n=13)$, we used a small and stable flow rate of $0.1 \mathrm{~m}^{3} \mathrm{~s}^{-1}$ for $f_{n}$.

\subsection{Calculating $\delta^{15} \mathrm{~N}$ and $\delta^{18} \mathrm{O}$ of remineralised nitrate}

To exclude the contribution of $\mathrm{NO}_{3}^{-}$(atm) from the $\delta^{15} \mathrm{~N}$ and $\delta^{18} \mathrm{O}$ values of nitrate (total) and to clarify the sources and behaviour of $\mathrm{NO}_{3}^{-}$(re) by using both $\delta^{15} \mathrm{~N}$ and $\delta^{18} \mathrm{O}$ as tracers, we estimated the end-member $\delta^{15} \mathrm{~N}$ and $\delta^{18} \mathrm{O}$ values of the remineralised nitrate portion, $\delta^{15} \mathrm{~N}_{\mathrm{re}}$ and $\delta^{18} \mathrm{O}_{\mathrm{re}}$, by excluding the contribution of $\mathrm{NO}_{3}^{-}$(atm) in nitrate (total; Tsunogai et al., 2010, 2011, 2014; Dejwakh et al., 2012; Liu et al., 2013; Riha et al., 2014) by using Eqs. (6) and (7):

$\begin{aligned} \delta^{15} \mathrm{~N}_{\mathrm{re}} & =\frac{C_{\text {total }} \cdot \delta^{15} \mathrm{~N}-C_{\mathrm{atm}} \cdot \delta^{15} \mathrm{~N}_{\mathrm{atm}}}{C_{\text {total }}-C_{\mathrm{atm}}}, \\ \delta^{18} \mathrm{O}_{\mathrm{re}} & =\frac{C_{\text {total }} \cdot \delta^{18} \mathrm{O}-C_{\mathrm{atm}} \cdot \delta^{18} \mathrm{O}_{\mathrm{atm}}}{C_{\text {total }}-C_{\mathrm{atm}}},\end{aligned}$

where $C_{\text {atm }}$ and $C_{\text {total }}$ denote the concentrations of $\mathrm{NO}_{3}^{-}$(atm) and nitrate (total) in each water sample respectively, and $\delta^{15} \mathrm{~N}_{\mathrm{atm}}, \delta^{18} \mathrm{O}_{\mathrm{atm}}$, and $\Delta^{17} \mathrm{O}_{\text {atm }}$ denote the $\delta^{15} \mathrm{~N}, \delta^{18} \mathrm{O}$, and $\Delta^{17} \mathrm{O}$ values of $\mathrm{NO}_{3}^{-}$(atm) in each sample respectively. The actual values of $\delta^{15} \mathrm{~N}_{\mathrm{atm}}, \delta^{18} \mathrm{O}_{\mathrm{atm}}$, and $\Delta^{17} \mathrm{O}_{\mathrm{atm}}$ used in this study were determined from the $\delta^{15} \mathrm{~N}, \delta^{18} \mathrm{O}$, and $\Delta^{17} \mathrm{O}$ values of nitrate in the wet deposition samples and are reported in Sect. 3.1 along with the ranges of errors. Please note that the errors in the estimated values of $\delta^{15} \mathrm{~N}_{\mathrm{re}}$ and $\delta^{18} \mathrm{O}_{\mathrm{re}}$ become larger in accordance with an increase in the $C_{\text {atm }} / C_{\text {total }}$ ratio due to the propagation law of errors, even if the errors in the values of $\delta^{15} \mathrm{~N}_{\mathrm{atm}}$ and $\delta^{18} \mathrm{O}_{\mathrm{atm}}$ are the same.

\subsection{Possible variations in $\Delta^{17} \mathrm{O}$ during the progress of partial removal and mixing}

Because we used the power law shown in Eq. (1) for the definition of $\Delta^{17} \mathrm{O}$, the $\Delta^{17} \mathrm{O}$ values are different from those based on the linear definition (Michalski et al., 2002). Please note that our $\Delta^{17} \mathrm{O}$ values would be $(0.1 \pm 0.1) \%$ higher for the stream water nitrate and $(0.9 \pm 0.3) \%$ o higher for the atmospheric nitrate if we had used the linear definition for calculation.

Compared with $\Delta^{17} \mathrm{O}$ values based on the linear definition, $\Delta^{17} \mathrm{O}$ values based on the power law definition are more stable during mass-dependent isotope fractionation processes, so we rated the $\Delta^{17} \mathrm{O}$ values of nitrate as always stable irrespective of any biogeochemical partial removal processes subsequent to deposition, such as assimilation or denitrification. However, $\Delta^{17} \mathrm{O}$ values based on the power law definition are not conserved during mixing processes between fractions with different $\Delta^{17} \mathrm{O}$ values, so the $C_{\text {atm }} / C_{\text {total }}$ ratios estimated using Eq. (2) are somewhat deviated from the actual $C_{\text {atm }} / C_{\text {total }}$ ratios in the samples. However, in this study, the extent of the deviations of the $C_{\text {atm }} / C_{\text {total }}$ ratios of the stream nitrate was less than $0.15 \%$, so we disregard this effect in the discussion.

\section{Results and discussion}

\subsection{Atmospheric nitrate}

The $\delta^{15} \mathrm{~N}, \delta^{18} \mathrm{O}$, and $\Delta^{17} \mathrm{O}$ of atmospheric nitrate $\mathrm{NO}_{3}^{-}$(atm) are shown in Fig. $3 \mathrm{a}-\mathrm{c}$ respectively as a function of sampling day (local time, UT + 09:00), and the daily depositional flux of $\mathrm{NO}_{3}^{-}$(atm) when each of the wet deposition samples was 

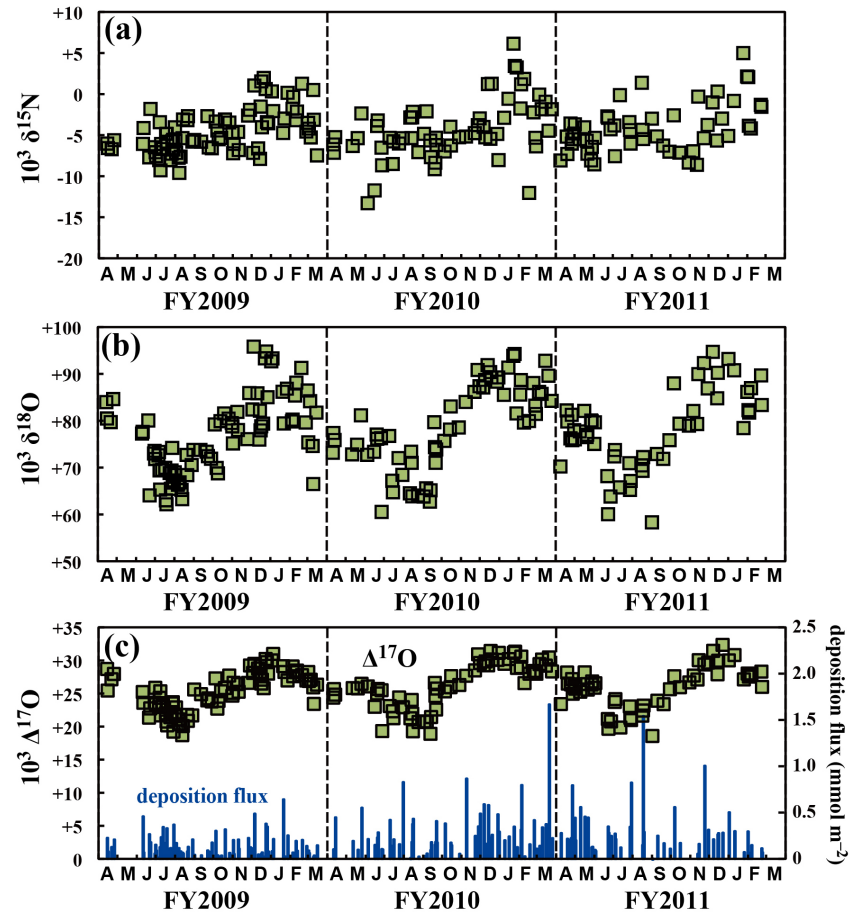

Figure 3. Temporal variations in the values of (a) $\delta^{15} \mathrm{~N}$, (b) $\delta^{18} \mathrm{O}$, and (c) $\Delta^{17} \mathrm{O}$ of nitrate in wet deposition recorded at the Sado-seki National Acid Rain Monitoring Station. The errors were smaller than the sizes of the symbols. The daily depositional flux of nitrate when each of the wet deposition samples was taken is also presented (c).

taken is also shown in Fig. 3c. The daily depositional flux of $\mathrm{NO}_{3}^{-}(\mathrm{atm})$ was calculated from the nitrate concentration and the daily precipitation (Table S2 in the Supplement).

The atmospheric nitrate at the Sado-seki monitoring station showed large ${ }^{17} \mathrm{O}$ excesses with $\Delta^{17} \mathrm{O}$ values from +18.6 to $+32.4 \%$ o. Moreover, a clear normal correlation between $\Delta^{17} \mathrm{O}$ and $\delta^{18} \mathrm{O}$ was shown $\left(r^{2}=0.878\right.$; Fig. 4). A similar trend was reported for atmospheric nitrate aerosols collected for a 1-year period in La Jolla, California $\left(32.7^{\circ} \mathrm{N}\right.$, 117.2 ${ }^{\circ} \mathrm{W}$; Michalski et al., 2003), and similar results also have been obtained in other areas of the world (Kaiser et al., 2007; Morin et al., 2009). Michalski et al. (2003) interpreted that the linear correlation corresponds to the mixing line between tropospheric ozone and tropospheric $\mathrm{H}_{2} \mathrm{O}$ and thus tropospheric $\mathrm{OH}$ radicals, with $\Delta^{17} \mathrm{O}=0 \%$ and $\delta^{18} \mathrm{O}=-5 \%$. However, the $\mathrm{NO}_{3}^{-}(\mathrm{atm})$ data obtained at the Sado-seki monitoring station showed a somewhat different trend in the $\Delta^{17} \mathrm{O}-\delta^{18} \mathrm{O}$ plot between summer, from May to October, and winter, from November to April (Fig. 4). Although the line fitted to the summer data showed a slope of $2.21 \pm 0.22$ and an intercept of $(+19.7 \pm 5.1) \%$ in the $\Delta^{17} \mathrm{O}-\delta^{18} \mathrm{O}$ plot, that of the winter data showed a statistically significant larger slope of $2.89 \pm 0.38$ and a smaller intercept of $(+3.0 \pm 9.2) \%$; all errors were in the $2 \sigma$ range.

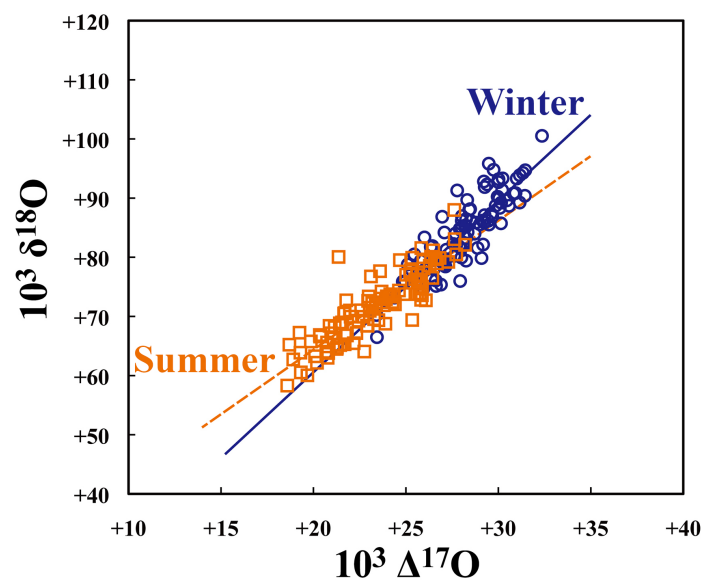

Figure 4. Relationship between $\Delta^{17} \mathrm{O}$ and $\delta^{18} \mathrm{O}$ for atmospheric nitrate in wet deposition. The errors were smaller than the size of the symbols. The blue circles represent data for winter, from November to March, whereas the orange squares represent data for summer, from April to October. The blue solid and orange dashed lines represent the least-squares fitted lines to the data of winter and summer respectively.

Although the winter data included an intercept of $-5 \%$ reported by Michalski et al. (2003) as the end-member $\delta^{18} \mathrm{O}$ value of the tropospheric $\mathrm{OH}$ radical within the possible error range, the intercept of summer data deviated strongly from the value. Because the monitoring station is located in the Asian monsoon area, the major air mass that arrived at the station was different seasonally: Pacific air originated from south-east was dominant in summer, whereas continental air originated from the north-west was dominant in winter. The present results imply seasonal and regional changes in the $\delta^{18} \mathrm{O} / \Delta^{17} \mathrm{O}$ ratios of tropospheric ozone and the $\mathrm{OH}$ radical.

On the basis of both the temporal variation in the daily depositional flux of $\mathrm{NO}_{3}^{-}(\mathrm{atm})$, shown in Fig. 3c, and the $\Delta^{17} \mathrm{O}$ value, we estimated the monthly average $\Delta^{17} \mathrm{O}$ value of $\mathrm{NO}_{3}^{-}(\mathrm{atm})\left(\Delta^{17} \mathrm{O}(\mathrm{m})\right)$ deposited at the Sado-seki monitoring station for each month (m) from April 2009 to March 2012 by using

$\Delta^{17} \mathrm{O}(\mathrm{m})=\frac{\sum_{k}\left(C_{k} \cdot V_{k} \cdot \Delta^{17} \mathrm{O}_{k}\right)}{\sum_{k}\left(C_{k} \cdot V_{k}\right)}$,

where $C_{k}$ denotes the concentration of nitrate in each wet deposition sample and $V_{k}$ denotes the total water volume of each wet deposition sample. Then, we estimated the annual and the 3-year average $\Delta^{17} \mathrm{O}$ values of $\mathrm{NO}_{3}^{-}(\mathrm{atm})\left(\Delta^{17} \mathrm{O}_{\text {avg }}\right)$ as $+25.5 \%$ or FY $2009,+27.2 \%$ for FY $2010,+25.7 \%$ or FY2011, and $+26.3 \%$ o for the 3 years by using

$\Delta^{17} \mathrm{O}_{\mathrm{avg}}=\frac{\sum_{m}\left(D(m) \cdot \Delta^{17} \mathrm{O}(m)\right)}{\sum_{m} D(m)}$, 
where $D(\mathrm{~m})$ denotes the monthly wet deposition rate of nitrate at the Sado-seki monitoring station determined by EANET (EANET, 2014). Because no wet deposition sample for measuring stable isotopes was taken in May 2009 or March 2012, we used the $\Delta^{17} \mathrm{O}(\mathrm{m})$ values of May 2010 and March 2011 respectively for these values. Substituting $\Delta^{17} \mathrm{O}$ with $\delta^{15} \mathrm{~N}\left(\delta^{18} \mathrm{O}\right)$ in Eqs. (8) and (9), we estimated $\delta^{15} \mathrm{~N}_{\mathrm{avg}}\left(\delta^{18} \mathrm{O}_{\mathrm{avg}}\right)$ as $-4.4 \%$ ( $+78.5 \%$ o for FY2009, $-3.8 \%$ o $(+81.8 \%$ o ) for FY2010, $-4.4 \%$ o $(+78.6 \%$ ) for FY2011, and $-4.2 \%$ ( $+79.8 \%$ o for the 3 years.

To apply the $\Delta^{17} \mathrm{O}_{\text {avg }}$ values for the 3 years obtained at the Sado-seki monitoring station as $\Delta^{17} \mathrm{O}$ of $\mathrm{NO}_{3}^{-}(\mathrm{atm})$ deposited on the studied watershed (i.e. $\Delta^{17} \mathrm{O}_{\text {atm }}$ in Eq. 2), additional corrections could be needed because the $\Delta^{17} \mathrm{O}$ value of $\mathrm{NO}_{3}^{-}(\mathrm{atm})$ is a function of the $\mathrm{NO}_{x}$ oxidation channels in the atmosphere, which shift depending on the intensity of sunlight, temperature, and oxidant levels (e.g. Michalski et al., 2003; Morin et al., 2008; Kunasek et al., 2008; Alexander et al., 2009; Morin et al., 2012; Savarino et al., 2013). The latitudinal difference between the Sado-seki monitoring station $\left(38^{\circ} 15^{\prime} \mathrm{N}, 138^{\circ} 24^{\prime} \mathrm{E}\right.$; Fig. 2$)$ and the watershed studied $\left(35^{\circ} 15^{\prime} \mathrm{N}, 136^{\circ} 5^{\prime} \mathrm{E}\right.$; Fig. 2) could change the intensity of sunlight and thus the $\mathrm{NO}_{x}$ oxidation channel. Moreover, Tsunogai et al. (2010) reported that nitrate in polluted air masses derived directly from megacities in winter showed slightly larger $\Delta^{17} \mathrm{O}$ values than nitrate in background air masses in the same seasons owing likely to the relative increase in the reaction via $\mathrm{NO}_{3}$ radicals within the entire $\mathrm{NO}_{3}^{-}(\mathrm{atm})$ production channel to produce $\mathrm{NO}_{3}^{-}(\mathrm{atm})$ in the polluted air mass. The annual average $\Delta^{17} \mathrm{O}$ value determined in this study was lowest in FY2009 when the deposition rate of nitrate was the smallest, at $19.3 \mathrm{mmol} \mathrm{m}^{-2} \mathrm{yr}^{-1}$ (EANET, 2014.), whereas the annual average $\Delta^{17} \mathrm{O}$ value was highest in FY2010 when the deposition rate was the largest, at $28.0 \mathrm{mmol} \mathrm{m}^{-2} \mathrm{yr}^{-1}$, within the 3 years of observation. These results also imply that the difference in the deposition rate of nitrate must be also corrected to apply the $\Delta^{17} \mathrm{O}_{\text {avg }}$ value to $\Delta{ }^{17} \mathrm{O}_{\text {atm }}$.

Nevertheless, both the annual average and the seasonal variation range of $\Delta^{17} \mathrm{O}$ correlated strongly with those determined at the Rishiri monitoring station $\left(45^{\circ} 07^{\prime} 11^{\prime \prime} \mathrm{N}\right.$, $141^{\circ} 12^{\prime} 33^{\prime \prime}$ E; Fig. 2) at $+26.2 \%$ in FY2008 (Tsunogai et al., 2010), where the wet deposition rate of $\mathrm{NO}_{3}^{-}(\mathrm{atm})$ was an average of $40 \%$ smaller than that at the Sado-seki monitoring station from 2000 to 2013 (EANET, 2014). Moreover, the values also coincided with those reported for midlatitudes, such as at La Jolla, at $33^{\circ} \mathrm{N}$ (Michalski et al., 2003), and at Princeton, at $40^{\circ} \mathrm{N}$ (Kaiser et al., 2007). We concluded that by allowing $1 \%$ of error, the standard deviation of the $\Delta{ }^{17} \mathrm{O}_{\text {avg }}$ values determined at the four different monitoring stations located within the same midlatitude range in the past,

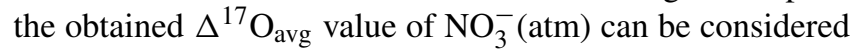
representative for middle latitudes worldwide, including the Lake Biwa watershed basin.
In addition, the actual $\Delta^{17} \mathrm{O}_{\text {atm }}$ values of $\mathrm{NO}_{3}^{-}(\mathrm{atm})$ in each stream water sample can differ from the $\Delta^{17} \mathrm{O}_{\text {avg }}$ owing to the seasonal variation in the $\Delta^{17} \mathrm{O}$ values of $\mathrm{NO}_{3}^{-}(\mathrm{atm})$. In correcting for the seasonal variation, however, it is not adequate to use the $\Delta^{17} \mathrm{O}$ values determined for the seasons of sampling as $\Delta{ }^{17} \mathrm{O}_{\mathrm{atm}}$ in Eq. (2), because the residence time of water is longer than a few months for most of the catchments in Japan with a humid temperate climate (Takimoto et al., 1994; Kabeya et al., 2007). That is, the nitrate in base flow stream water had been stored previously in subsurface runoff and groundwater, for which seasonal $\Delta^{17} \mathrm{O}$ changes have not been found thus far (Tsunogai et al., 2010; Nakagawa et al., 2013). We concluded that by allowing an additional $1.8 \%$ o of error, the standard deviation of the 6-month moving average of atmospheric nitrate determined at the Sado monitoring station in this study, the obtained $\Delta^{17} \mathrm{O}_{\mathrm{avg}}$ value of $\mathrm{NO}_{3}^{-}(\mathrm{atm})$ represented those eluted from the Lake Biwa watershed basin.

In summary, we used the 3-year average $\Delta^{17} \mathrm{O}$ value of $\mathrm{NO}_{3}^{-}(\mathrm{atm})$ obtained at the Sado-seki monitoring station in this study $\left(\Delta^{17} \mathrm{O}_{\text {avg }}=+26.3 \%\right.$ o $)$ as the $\Delta^{17} \mathrm{O}_{\text {atm }}$ in Eq. (2) to estimate $C_{\text {atm }}$ in the streams of the Lake Biwa watershed basin by allowing an error range of $3 \%$, considering the factor changes of $\Delta^{17} \mathrm{O}_{\text {atm }}$ from $\Delta{ }^{17} \mathrm{O}_{\text {avg }}$ described above. About $65 \%$ of all of the $\Delta^{17} \mathrm{O}$ data of $\mathrm{NO}_{3}^{-}$(atm) obtained at the Sado-seki monitoring station were included in this range of $(+26.3 \pm 3.0) \%$.

In the case of the $\delta^{15} \mathrm{~N}$ and $\delta^{18} \mathrm{O}$ of $\mathrm{NO}_{3}^{-}$(atm) in each stream water sample (i.e. $\delta^{15} \mathrm{~N}_{\mathrm{atm}}$ and $\delta^{18} \mathrm{O}_{\mathrm{atm}}$ in Eqs. 6 and 7), the values differed further from $\delta^{15} \mathrm{~N}_{\mathrm{avg}}$ and $\delta^{18} \mathrm{O}_{\mathrm{avg}}$ owing to isotopic fractionation during partial removal subsequent to deposition. As a result, while using the 3-year average values of $\delta^{15} \mathrm{~N}\left(\delta^{15} \mathrm{~N}_{\mathrm{avg}}=-4.2 \%\right)$ and $\delta^{18} \mathrm{O}\left(\delta^{18} \mathrm{O}_{\mathrm{avg}}=\right.$ $+79.8 \%$ ) as $\delta^{15} \mathrm{~N}_{\mathrm{atm}}$ and $\delta^{18} \mathrm{O}_{\mathrm{atm}}$, we assumed much a larger error range in the values, i.e. $\pm 10 \%$ for both $\delta^{15} \mathrm{~N}$ and $\delta^{18} \mathrm{O}$, twice the enrichment factor during assimilation of nitrate. Because the concentration of atmospheric nitrate would be reduced to $e^{-2}$ of the original value if $\delta^{15} \mathrm{~N}$ and $\delta^{18} \mathrm{O}$ values increased $+10 \%$ o from their original values through assimilation, it might be difficult to detect atmospheric nitrate within total nitrate. Of course, this estimation is less reliable, and we further discuss the appropriateness of these error ranges in Sect. 3.3. Because of the small $C_{\text {atm }} / C_{\text {total }}$ ratios of stream water of generally less than $7 \%$ (Sect. 3.2), the error propagated to $\delta^{15} \mathrm{~N}_{\mathrm{re}}$ and $\delta^{18} \mathrm{O}_{\mathrm{re}}$ was generally small, less than 1 and $2 \%$ respectively for most of the data presented in this study (Table S5).

\subsection{Stream nitrate overview}

The concentrations $\left(C_{\text {total }}\right)$ and the $\delta^{15} \mathrm{~N}, \delta^{18} \mathrm{O}$, and $\Delta^{17} \mathrm{O}$ values of nitrate in the stream water samples determined for each observation $(n=12,3$, and 4$)$ are presented in Fig. 5a-d. The annual average concentration $\left(\bar{C}_{\text {total }}\right)$ and the 

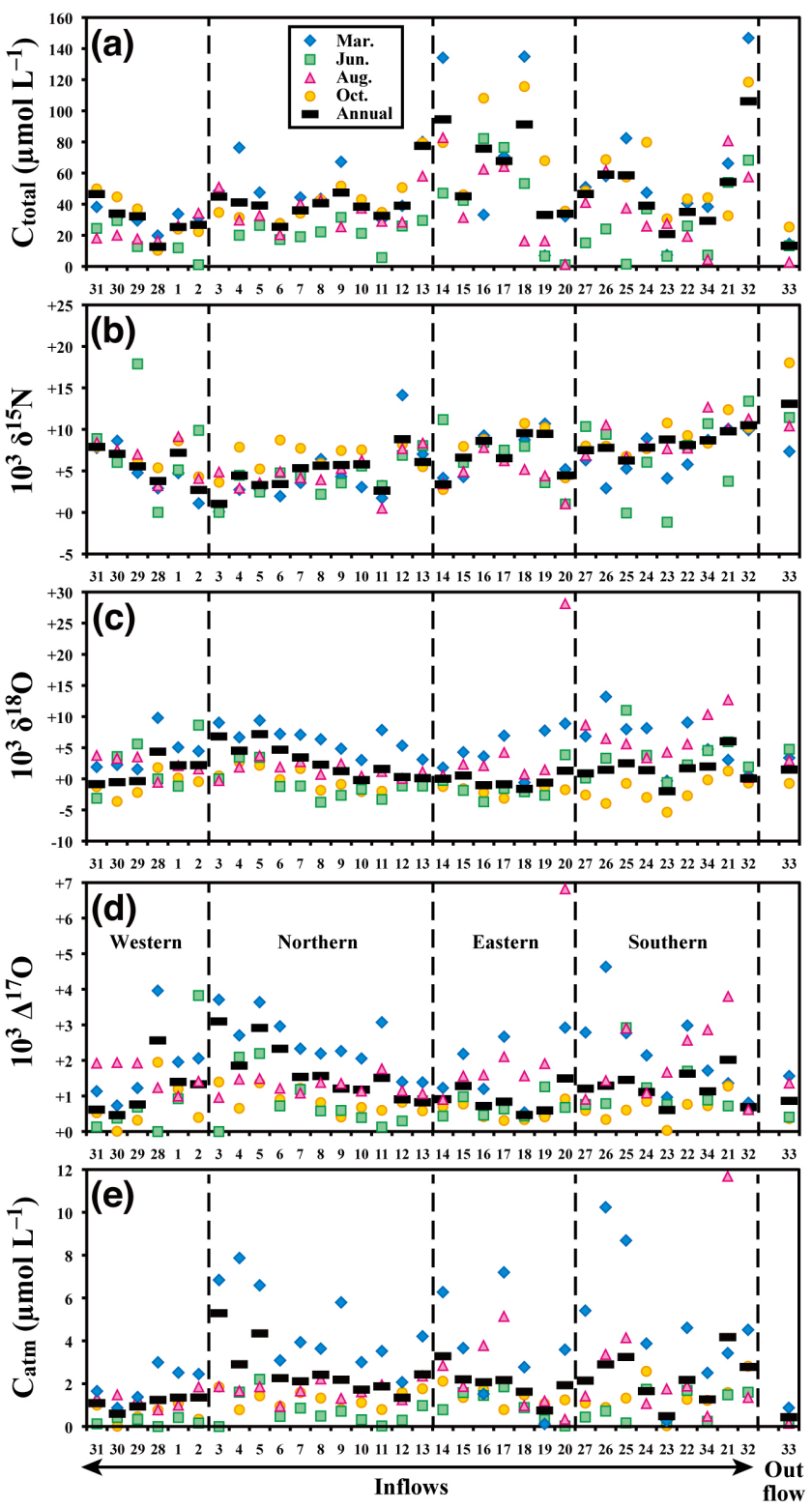

Figure 5. Distribution of (a) total concentrations, (b) $\delta^{15} \mathrm{~N}$, (c) $\delta^{18} \mathrm{O}$, and (d) $\Delta^{17} \mathrm{O}$ for nitrate and (e) atmospheric nitrate concentrations in inflow streams by the various station numbers and the outflow station no. 33 in the Lake Biwa watershed in March (blue diamonds), June (green squares), August (red triangles), and October (orange circles) 2013 together with the annual averages for each river (black bars). The errors were smaller than the sizes of the symbols except for (e).

annual average $\delta^{15} \mathrm{~N}, \delta^{18} \mathrm{O}$, and $\Delta^{17} \mathrm{O}$ values $\left(\overline{\delta^{15} \mathrm{~N}}, \overline{\delta^{18} \mathrm{O}}\right.$, and $\overline{\Delta^{17} \mathrm{O}}$ respectively) in each stream estimated by using Eqs. (3), (4), and (5) are shown in the figure as black bars. In this figure, each stream was plotted on the $x$ axis in the order of location, beginning from stream no. 31, which lies south-west of all of the streams (Fig. 2), and proceeding in a clockwise direction. The errors are comparable to the sizes of

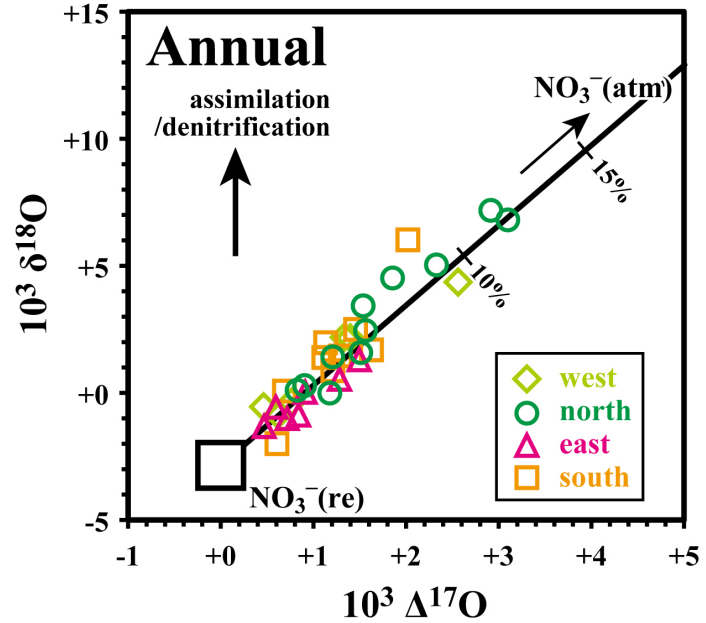

Figure 6. Relationship of the annual average values of $\Delta^{17} \mathrm{O}$ and $\delta^{18} \mathrm{O}$ of $\mathrm{NO}_{3}^{-}$in the inflow streams. The symbols represent the location of each river (west: yellowish green diamonds; north: green circles; east: red triangles; south: orange squares). A hypothetical mixing line between atmospheric nitrate $\left(\mathrm{NO}_{3}^{-}(\mathrm{atm})\right)$ and remineralised nitrate $\left(\mathrm{NO}_{3}^{-}(\mathrm{re})\right)$ is shown together with the end-member value of $\mathrm{NO}_{3}^{-}$(re) (large white square) and the 10 and $15 \%$ mole fractions of $\mathrm{NO}_{3}^{-}(\mathrm{atm})$ on the line. The errors were smaller than the sizes of the symbols.

the symbols in Fig. 5a-d. The spatially continuous variation of the values of $\overline{\delta^{15} \mathrm{~N}}, \overline{\delta^{18} \mathrm{O}}$, and $\overline{\delta^{17} \mathrm{O}}$ imply that the values may represent land use changes in each catchment area.

Although the $\Delta^{17} \mathrm{O}$ values presented significant spatial and temporal variation from +0.0 to $+6.8 \%$, the range of the $\overline{\Delta{ }^{17} \mathrm{O}}$ values from +0.5 to $+3.1 \%$ was typical for nitrate in natural stream water (Michalski et al., 2004; Tsunogai et al., 2010, 2014; Liu et al., 2013; Rose et al., 2015). These results correspond to mole fractions of unprocessed $\mathrm{NO}_{3}^{-}(\mathrm{atm})$ to total nitrate from $(1.8 \pm 0.3)$ to $(11.8 \pm 1.3) \%$, obtained by using Eq. (2).

By using the concentration $\left(C_{\text {total }}\right)$ and the $\Delta^{17} \mathrm{O}$ values of nitrate, the $\mathrm{NO}_{3}^{-}(\mathrm{atm})$ concentration $\left(C_{\mathrm{atm}}\right)$ was calculated using Eq. (2) and is plotted in Fig. 5e. In addition, the annual average concentration of $\mathrm{NO}_{3}^{-}(\mathrm{atm})\left(\bar{C}_{\mathrm{atm}}\right)$ in stream nitrate was calculated and is also presented in Fig. 5e as black bars. Please note that the errors in $C_{\text {atm }}$ and $\bar{C}_{\text {atm }}$ are not presented in Fig. 5e (see Table $\mathrm{S} 4$ for the respective ranges of errors).

To verify possible secular changes (i.e. long-term nonperiodic variation), the estimated $\bar{C}_{\text {total }}, \overline{\delta^{15} \mathrm{~N}}$, and $\overline{\delta^{18} \mathrm{O}}$ for each stream were compared with those determined by Ohte et al. (2010), in which annual average concentration and annual average $\delta^{15} \mathrm{~N}$ and $\delta^{18} \mathrm{O}$ values of nitrate (total) were determined for the same streams in 2004 to 2006. Although both concentrations and $\delta^{15} \mathrm{~N}$ and $\delta^{18} \mathrm{O}$ values in the streams showed significant spatial and temporal variations during 2013, as presented in Fig. 5, the annual average values al- 
most correlated with the values determined in 2004 to 2006 (Fig. S1 in the Supplement). The average differences from the values determined in the streams in 2004 to 2006 were $+5.3 \mu \mathrm{mol} \mathrm{L}^{-1}$ for $\bar{C}_{\text {total }},+0.6 \%$ for $\overline{\delta^{15} \mathrm{~N}}$, and $+1.6 \%$ for $\overline{\delta^{18} \mathrm{O}}$, whereas the standard deviation ranges of the differences were $14.9 \mu \mathrm{mol} \mathrm{L}^{-1}$ for $\bar{C}_{\text {total }}, 1.6 \%$ for $\overline{\delta^{15} \mathrm{~N}}$, and $2.1 \%$ for $\overline{\delta^{18} \mathrm{O}}$. That is, the differences from the values determined in 2004 to 2006 were smaller than their standard deviation ranges, so the differences were not significant. We concluded that secular changes were minimal for nitrate in the streams, at least for the most recent 10 -year period of observations.

\subsection{Relationship between $\Delta^{17} \mathrm{O}$ and $\delta^{18} \mathrm{O}$}

One of the features in the spatial variation shown in Fig. 5 is the positive correlation between $\Delta^{17} \mathrm{O}$ and $\delta^{18} \mathrm{O}$. As is clearly represented by the relationship between $\overline{\Delta^{17} \mathrm{O}}$ and $\overline{\delta^{18} \mathrm{O}}$ (Fig. 6), these values showed linear correlation with an $r^{2}$ value of 0.88 . Because $\mathrm{NO}_{3}^{-}(\mathrm{atm})$ is characterised by highly elevated values of both $\Delta^{17} \mathrm{O}$ and $\delta^{18} \mathrm{O}$ (Figs. 3 and 4), changes in the mole fraction of unprocessed $\mathrm{NO}_{3}^{-}$(atm) within the total nitrate pool must be responsible for the positive correlation between $\overline{\Delta^{17} \mathrm{O}}$ and $\overline{\delta^{18} \mathrm{O}}$ for nitrate in the streams.

The slope value of the least-squares-fitted line between $\overline{\Delta^{17} \mathrm{O}}$ and $\overline{\delta^{18} \mathrm{O}}$ (Fig. 6) also supports this hypothesis. By extrapolating the least-squares-fitted line to the region of $\mathrm{NO}_{3}^{-}(\mathrm{atm})$ with a $\Delta^{17} \mathrm{O}$ value of $+26.3 \%$, we obtained $\delta^{18} \mathrm{O}=(+86 \pm 7) \%$, which also corresponds with the average $\delta^{18} \mathrm{O}$ value of $\mathrm{NO}_{3}^{-}(\mathrm{atm})$ of $+79.8 \%$ obtained in Sect. 3.1. We concluded that the $\overline{\delta^{18} \mathrm{O}}$ values also primarily reflect the mole fraction of $\mathrm{NO}_{3}^{-}(\mathrm{atm})$ within nitrate.

Without $\Delta^{17} \mathrm{O}$ data and without some assumptions, it was difficult to decide the major factor controlling the $\delta^{18} \mathrm{O}$ values of the stream nitrate. However, by adding $\Delta^{17} \mathrm{O}$ data, as presented above, it became apparent that the changes in the mole fraction of unprocessed $\mathrm{NO}_{3}^{-}(\mathrm{atm})$ within the total nitrate pool were primarily responsible for the $\delta^{18} \mathrm{O}$ variation between the streams. These results further support our hypothesis, presented in Sect. 1, that interpretations on the stable isotopic compositions of nitrate $\left(\delta^{15} \mathrm{~N}\right.$ and $\left.\delta^{18} \mathrm{O}\right)$ made without $\Delta^{17} \mathrm{O}$ values can often be misleading. When using stable isotopic compositions, particularly the $\delta^{18} \mathrm{O}$ value, of nitrate in freshwater environments to trace its sources and fate, the determination of $\Delta{ }^{17} \mathrm{O}$ values is essential.

By extrapolating the linear correlation between $\overline{\Delta^{17} \mathrm{O}}$ and $\overline{\delta^{18} \mathrm{O}}$ to $\overline{\Delta^{17} \mathrm{O}}=0 \%$, we obtained the $\delta^{18} \mathrm{O}$ value of $(-2.9 \pm 1.2) \%$ as the average $\delta^{18} \mathrm{O}$ value of the remineralised portion of nitrate $\left(\mathrm{NO}_{3}^{-}(\mathrm{re})\right)$ in the streams. Although the $\delta^{18} \mathrm{O}$ value was substantially ${ }^{18} \mathrm{O}$ depleted compared with that produced through microbial nitrification in soil during in vitro incubation experiments in past studies
(Mayer et al., 2001; Burns and Kendall, 2002; Spoelstra et al., 2007), it correlated strongly with the $\delta^{18} \mathrm{O}$ values of $\mathrm{NO}_{3}^{-}$(re) determined recently by using the linear relationship between $\Delta^{17} \mathrm{O}$ and $\delta^{18} \mathrm{O}$ of nitrate eluted from forested watersheds, such as $\mathrm{NO}_{3}^{-}(\mathrm{re})$ in the groundwater of cooltemperate forested watersheds at $(-4.2 \pm 2.4) \%$, where the $\delta^{18} \mathrm{O}\left(\mathrm{H}_{2} \mathrm{O}\right)$ was around $-13 \%$ (Tsunogai et al., 2010), and $\mathrm{NO}_{3}^{-}(\mathrm{re})$ in stream water in a cool-temperate forested watershed at $(-3.6 \pm 0.7) \%$, where the $\delta^{18} \mathrm{O}\left(\mathrm{H}_{2} \mathrm{O}\right)$ was around $-11 \%$ (Tsunogai et al., 2014). Moreover, the $\delta^{18} \mathrm{O}$ value of $\mathrm{NO}_{3}^{-}$(re) obtained in this study, $(-2.9 \pm 1.2) \%$, is close to the possible lowermost $\delta^{18} \mathrm{O}$ value of $\mathrm{NO}_{3}^{-}$(re) (Buchwald et al., 2012) produced through microbial nitrification under $\mathrm{H}_{2} \mathrm{O}$ of $(-7.8 \pm 1.0) \%$ o (the average and the standard deviation of the $\delta^{18} \mathrm{O}$ values of $\mathrm{H}_{2} \mathrm{O}$ of the streams; Table $\mathrm{S} 3$ ). Furthermore, the $\delta^{18} \mathrm{O}$ value of $\mathrm{NO}_{3}^{-}(\mathrm{re})$ correlates strongly with that obtained through in vitro incubation experiments in recent studies that simulated temperate forest soils (Fang et al., 2012). We concluded that the $\delta^{18} \mathrm{O}$ value of $\mathrm{NO}_{3}^{-}$(re) produced through nitrification in the temperate watershed with a $\delta^{18} \mathrm{O}\left(\mathrm{H}_{2} \mathrm{O}\right)$ value of $(-7.8 \pm 1.0) \%$ o was $(-2.9 \pm 1.2) \%$ and that we should use such a low $\delta^{18} \mathrm{O}$ value for the $\mathrm{NO}_{3}^{-}$(re) produced through nitrification in the watershed. Understanding the relationship between $\Delta^{17} \mathrm{O}$ and $\delta^{18} \mathrm{O}$ of nitrate shown in Fig. 6 is highly useful for determining the $\delta^{18} \mathrm{O}$ value of $\mathrm{NO}_{3}^{-}$(re) in each watershed (Tsunogai et al., 2010).

Although the $\Delta^{17} \mathrm{O}$ values of nitrate were stable during partial biogeochemical processing, such as partial removal through assimilation or denitrification, the $\delta^{18} \mathrm{O}$ values of nitrate could vary through the isotopic fractionation processes within each catchment area. Nevertheless, the $\overline{\delta^{18} \mathrm{O}}$ values of nitrate in the streams plotted on the mixing line between the $\mathrm{NO}_{3}^{-}(\mathrm{atm})$ that had been deposited in the watershed and $\mathrm{NO}_{3}^{-}$(re) with $\delta^{18} \mathrm{O}$ and $\Delta^{17} \mathrm{O}$ values close to those produced through nitrification in the catchments. Thus, we concluded that the range of isotopic fractionations owing to partial removal through assimilation or denitrification subsequent to deposition of $\mathrm{NO}_{3}^{-}(\mathrm{atm})$ or production of $\mathrm{NO}_{3}^{-}(\mathrm{re})$ within each catchment area was generally small for the major portion of nitrate eluted from the watershed. If such isotopic fractionations were significant for the portion of $\mathrm{NO}_{3}^{-}(\mathrm{atm})$ in total nitrate, the data should plot on the ${ }^{18} \mathrm{O}$-enriched side of Fig. 6, especially for those data enriched in $\mathrm{NO}_{3}^{-}(\mathrm{atm})$ (i.e. those showing high $\Delta^{17} \mathrm{O}$ values). This result also supports our assumption in Sect. 3.1 that the actual $\delta^{15} \mathrm{~N}$ and $\delta^{18} \mathrm{O}$ values of $\mathrm{NO}_{3}^{-}(\mathrm{atm})$ in each stream water sample $\left(\delta^{15} \mathrm{~N}_{\mathrm{atm}}\right.$ and $\delta^{18} \mathrm{O}_{\text {atm }}$ in Eqs. 6 and 7) correlate with the $\delta^{15} \mathrm{~N}_{\mathrm{avg}}$ and $\delta^{18} \mathrm{O}_{\text {avg }}$ estimated at the Sado-seki monitoring station within an error of $\pm 10 \%$.

\section{4 $\delta^{15} \mathrm{~N}$ values of remineralised nitrate in streams}

To trace the source of the ${ }^{18} \mathrm{O}$-depleted $\mathrm{NO}_{3}^{-}$(re) eluted from the watershed into the lake, the annual average $\delta^{15} \mathrm{~N}$ and 

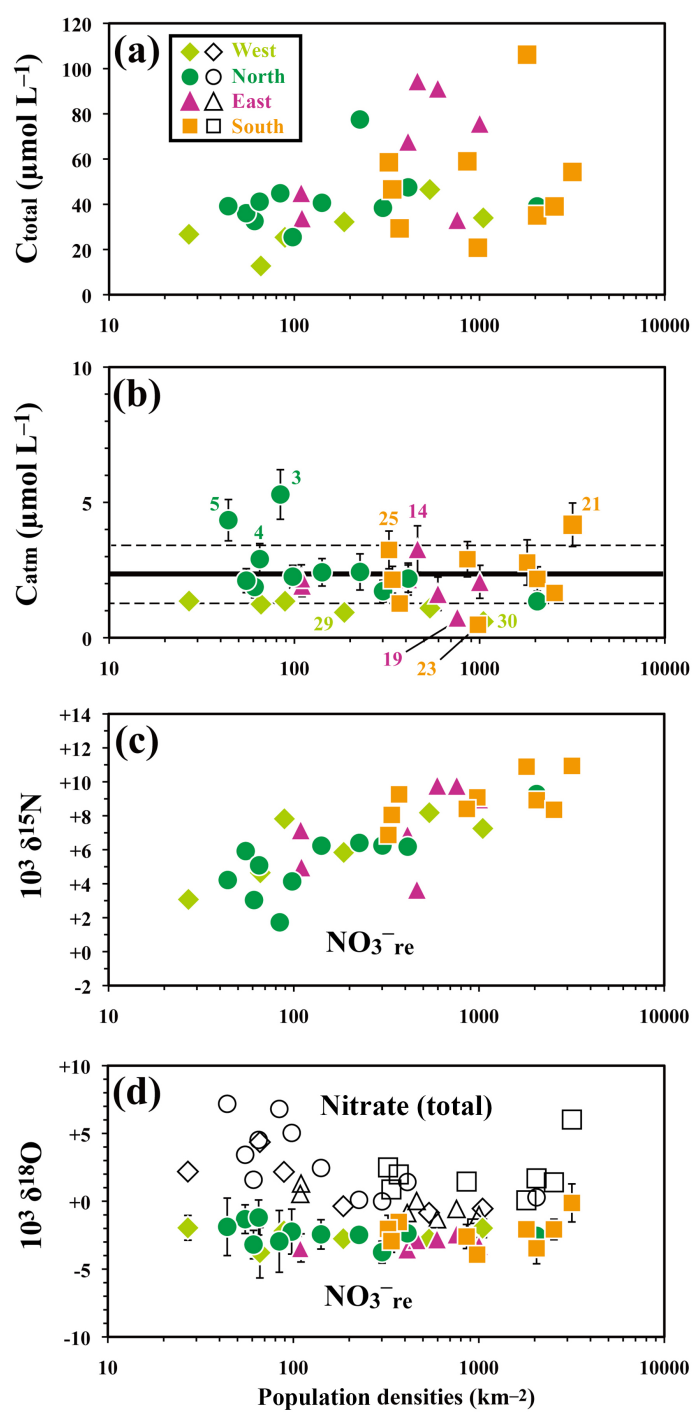

Figure 7. Annual average concentration of (a) nitrate $\left(C_{\text {total }}\right)$ and (b) $\mathrm{NO}_{3}^{-}(\mathrm{atm})\left(C_{\text {atm }}\right)$ in each inflow stream plotted as a function of the population density in each catchment, together with (c) the annual average value of $\delta^{15} \mathrm{~N}$ and (d) that of $\delta^{18} \mathrm{O}$ for remineralised $\mathrm{NO}_{3}^{-}\left(\mathrm{NO}_{3}^{-}(\mathrm{re})\right)$. The annual average $\delta^{18} \mathrm{O}$ values of nitrate (total) are also presented in (d). The symbols represent the location of each river (west: diamonds; north: circles; east: triangles; south: squares). The errors larger than the sizes of the symbols are presented by error bars. Some of the streams in (b) are indicated by number.

$\delta^{18} \mathrm{O}$ values of the remineralised portion of nitrate $\left(\bar{\delta}^{15} \mathrm{~N}_{\mathrm{re}}\right.$ and $\bar{\delta}^{18} \overline{\mathrm{O}}_{\mathrm{re}}$ ) in each inflow stream were estimated using Eqs. (6) and (7) and are plotted as a function of population density in Fig. 7c and d respectively. The original $\overline{\delta^{18} \mathrm{O}}$ is also in Fig. 7d. Because of the large $\delta^{18} \mathrm{O}$ differences of about $80 \%$ between the nitrate in streams and the $\mathrm{NO}_{3}^{-}(\mathrm{atm})$, the $\delta^{18} \mathrm{O}_{\mathrm{re}}$ values were a few $\%$ lower than each original $\delta^{18} \mathrm{O}$ value in total nitrate (Fig. 7d). On the contrary, because of the small $\delta^{15} \mathrm{~N}$ differences of less than $15 \%$ o between the total nitrate in streams and $\mathrm{NO}_{3}^{-}(\mathrm{atm})$, as well as the small $C_{\text {atm }} / C_{\text {total }}$ ratios in the streams, most of the $\delta^{15} \mathrm{~N}_{\text {re }}$ values showed small deviations of less than $1 \%$ o from each corresponding original $\delta^{15} \mathrm{~N}$ value in the total nitrate in most of the streams, so the original $\overline{\delta^{15} \mathrm{~N}}$ values are not presented in Fig. 7c. Although the annual average $\bar{\delta}_{{ }^{18} \mathrm{O}_{\text {re }}}$ values were low and almost uniform, from -4.0 to $-0.1 \%$, as implied in the linear correlation between $\overline{\Delta^{17} \mathrm{O}}$ and $\overline{\delta^{18} \mathrm{O}}$ in Fig. $6, \bar{\delta}^{15} \mathrm{~N}_{\mathrm{re}}$ showed larger variation from +1.7 to $+10.9 \%$.

Moreover, $\bar{\delta}^{15} \bar{N}_{\text {re }}$ showed positive linear correlation with the population density in logarithmic scale $\left(r^{2}=0.64\right.$, $p<0.001$; Fig. 7c). A similar trend was reported for the $\delta^{15} \mathrm{~N}$ values of total nitrate $\left(=\mathrm{NO}_{3}^{-}(\mathrm{atm})+\mathrm{NO}_{3}^{-}(\mathrm{re})\right)$ in past studies in this watershed (Ohte et al., 2010) and others (Mayer et al., 2002). We further verified that the remineralised portion of nitrate $\left(\mathrm{NO}_{3}^{-}(\mathrm{re})\right)$ was responsible for the positive correlation between the $\delta^{15} \mathrm{~N}$ values of total nitrate and population density that has been found often in various streams in the world.

Both the concentrations and the isotopic compositions shown in Fig. 7 clearly demonstrate that most portions of the nitrate eluted from the catchments with lower population densities of less than $100 \mathrm{~km}^{-2}$, showing $\delta^{15} \mathrm{~N}$ values of $(+4.4 \pm 1.8) \%$ and $\delta^{18} \mathrm{O}$ values of about $(-2.3 \pm 0.9) \%$, were produced through nitrification in naturally occurring soil organic matter (Kendall et al., 1995; Ohte et al., 2010). In the latter half of this section, we discuss the source of the ${ }^{15} \mathrm{~N}$-enriched $\mathrm{NO}_{3}^{-}(\mathrm{re})$ eluted from the catchments with higher population densities of more than $1000 \mathrm{~km}^{-2}$, showing $\delta^{15} \mathrm{~N}$ values of $(+9.2 \pm 1.3) \%$ or more and $\delta^{18} \mathrm{O}$ values of about $(-2.2 \pm 1.1) \%$.

Denitrification in riverbed sediments adjacent to riparian zones or groundwater bodies (McMahon and Böhlke, 1996) can increase the $\delta^{15} \mathrm{~N}$ value of stream nitrate. However, if such post-production alternation were responsible for the ${ }^{15} \mathrm{~N}$ enrichment of $\mathrm{NO}_{3}^{-}(\mathrm{re})$ and thus the total nitrate, the values of $\delta^{18} \mathrm{O}_{\mathrm{re}}$ in addition to those of $\delta^{15} \mathrm{~N}_{\mathrm{re}}$ would be increased (Granger et al., 2008). Moreover, the absolute concentration of $\mathrm{NO}_{3}^{-}(\mathrm{atm})\left(C_{\mathrm{atm}}\right)$ would decrease in accordance with the progress of denitrification, but the observed $C_{\text {atm }}$ was almost uniform irrespective of population density. Of course, the initial $C_{\text {atm }}$ could vary between the streams. However, to explain the observed uniform $C_{\text {atm }}$, unrealistic assumptions are needed for $C_{\text {atm }}$, such as the initial $C_{\text {atm }}$ being higher in accordance with higher population density. The low and uniform $\delta^{18} \mathrm{O}_{\text {re }}$ values (Fig. $7 \mathrm{~d}$ ) as well as the uniform $C_{\text {atm }}$ irrespective of population density (Fig. 7b) imply that denitrification in riverbed sediments was minor for the nitrate in the streams. Rather, the $\mathrm{NO}_{3}^{-}(\mathrm{re})$ must be enriched in ${ }^{15} \mathrm{~N}$ from its initial production through nitrification within the catchments with high population densities. In addition, the small differences in $\delta^{18} \mathrm{O}$ values of $\mathrm{NO}_{3}^{-}(\mathrm{re})$ between those values irrespective of the population densities in the catchment area (Fig. 7d) imply that the essential parameters 

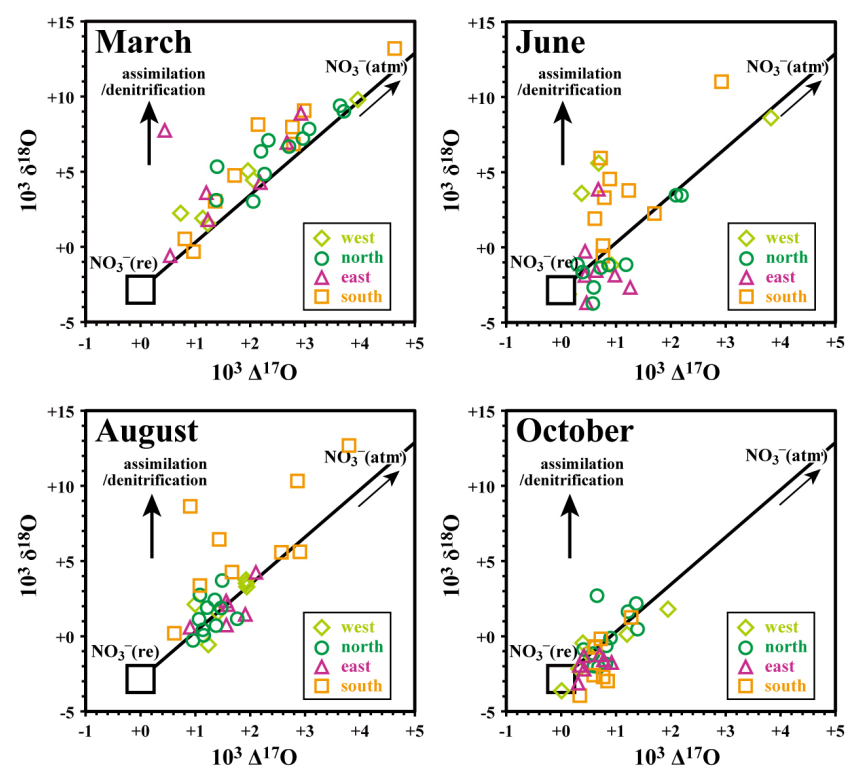

Figure 8. Temporal changes in the relationship between the values of $\Delta^{17} \mathrm{O}$ and $\delta^{18} \mathrm{O}$ of the total nitrate in the stream water. The symbols are the same as those in Fig. 6. A hypothetical mixing line between atmospheric nitrate $\left(\mathrm{NO}_{3}^{-}(\mathrm{atm})\right)$ and remineralised nitrate $\left(\mathrm{NO}_{3}^{-}\right.$(re)) is also shown together with the end-member value of $\mathrm{NO}_{3}^{-}$(re) (large white square). The errors were smaller than the sizes of the symbols.

for determining the $\delta^{18} \mathrm{O}$ values of nitrate during nitrification, such as the $\delta^{18} \mathrm{O}$ values of $\mathrm{H}_{2} \mathrm{O}$ and the $\mathrm{pH}$ of soils (Buchwald et al., 2012; Fang et al., 2012), should be similar among them.

Based on the $\delta^{15} \mathrm{~N}$ values of total nitrate eluted from catchments with high population densities, as well as the positive correlation between the $\delta^{15} \mathrm{~N}$ values of total nitrate and the population densities, Ohte et al. (2010) proposed sewage effluent as the dominant source contributing to the increase in the $\delta^{15} \mathrm{~N}$ values of total nitrate eluted from such catchments. The $\delta^{15} \mathrm{~N}$ and $\delta^{18} \mathrm{O}$ values of $\mathrm{NO}_{3}^{-}(\mathrm{re})$ newly estimated in this study, $(+9.2 \pm 1.3) \%$ or more and $(-2.2 \pm 1.1) \%$ respectively, also imply that the dominant source contributing to the increase in the $\delta^{15} \mathrm{~N}$ values of total nitrate had been produced through nitrification in which the source $\mathrm{N}$ of the nitrate had already been enriched in ${ }^{15} \mathrm{~N}$. Although the $\delta^{15} \mathrm{~N}$ and $\delta^{18} \mathrm{O}$ values of total nitrate in sewage effluent determined in past studies (Aravena et al., 1993; Widory et al., 2005; Wankel et al., 2006; Xue et al., 2009) were a few per mille higher than the $\delta^{15} \mathrm{~N}$ and $\delta^{18} \mathrm{O}$ values of $\mathrm{NO}_{3}^{-}$(re) eluted from the high population density catchments, $\delta^{15} \mathrm{~N}_{\mathrm{re}}=(+9.2 \pm 1.3) \% \circ$ and $\delta^{18} \mathrm{O}_{\mathrm{re}}=(-2.2 \pm 1.1) \%$, the slight deviations in the reported $\delta^{15} \mathrm{~N}$ and $\delta^{18} \mathrm{O}$ values from our results can be explained by several factors, such as (1) a slight contribution of $\mathrm{NO}_{3}^{-}(\mathrm{atm})$ and (2) the progress of denitrification subsequent to production. We concluded that sewage effluent was the most probable pollution source of nitrate to explain the observed concentrations and isotopic compositions of nitrate eluted from the catchments with high population densities, particularly for those of more than $1000 \mathrm{~km}^{-2}$.

\subsection{Seasonal variation}

Although the annual average values of $\Delta^{17} \mathrm{O}$ and $\delta^{18} \mathrm{O}$ in each stream, $\overline{\Delta^{17} \mathrm{O}}$ and $\overline{\delta^{18} \mathrm{O}}$ respectively, showed linear correlation, as presented in Fig. 6, the same results were not always attained for those in each season. Particularly for those values obtained during June and August (i.e. summer), some of the streams showed significant deviations in $\delta^{18} \mathrm{O}$ of more than a few per mille from the hypothetical mixing line between $\mathrm{NO}_{3}^{-}(\mathrm{atm})\left(\Delta^{17} \mathrm{O}=+26.3\right.$ and $\delta^{18} \mathrm{O}=+79.8 \%$ o $)$ and $\mathrm{NO}_{3}^{-}(\mathrm{re})\left(\Delta^{17} \mathrm{O}=0\right.$ and $\delta^{18} \mathrm{O}=-2.9 \%$; Fig. 8). Even though the values of $\Delta^{17} \mathrm{O}$ and $\delta^{18} \mathrm{O}$ of $\mathrm{NO}_{3}^{-}(\mathrm{atm})$ showed seasonal variation, as presented in Figs. 3 and 4, the large deviations from the mixing line could not be explained based on the seasonal changes in $\mathrm{NO}_{3}^{-}(\mathrm{atm})$. Rather, we must assume some seasonal changes in the biogeochemical nitrogen cycles within each catchment area to explain the relationship because, unlike the $\Delta^{17} \mathrm{O}$ values, the $\delta^{18} \mathrm{O}$ values of nitrate could vary during biogeochemical processing within each catchment area. As a result, we can evaluate the seasonal changes in the biogeochemical processing within each catchment area by using the seasonal changes in the relationship between $\Delta^{17} \mathrm{O}$ and $\delta^{18} \mathrm{O}$ shown in Fig. 8 .

The increases in the number of data deviated from the hypothetical mixing line by more than a few per mille from the hypothetical mixing line in June and August, especially those plotted on the ${ }^{18} \mathrm{O}$-enriched region (i.e. vertically upward direction in the figures), imply that partial nitrate removal through assimilation or denitrification was active within each catchment area in these months. The spatial differences in the ${ }^{18} \mathrm{O}$ enrichment also support this hypothesis. As presented in Fig. 8 by the orange squares, ${ }^{18} \mathrm{O}$ enrichment was common in samples obtained from the southern streams with high population densities in their catchment areas. We can assume elevated loading of both nutrients and organic matter of anthropogenic origin in these catchments, both of which naturally enhance assimilation and denitrification.

In contrast, most samples obtained during March and October were distributed on the hypothetical mixing line between $\mathrm{NO}_{3}^{-}(\mathrm{atm})$ and $\mathrm{NO}_{3}^{-}(\mathrm{re})$, as presented in Fig. 8. We concluded that the range of isotopic fractionation subsequent to production, such as partial removal through assimilation or denitrification, in winter was generally small for the major portion of nitrate eluted from the watershed and fed into the lake. Therefore, the annual average values (i.e. $\overline{\delta^{18} \mathrm{O}}$ and $\left.\overline{\Delta^{17} \mathrm{O}}\right)$ of the streams distributed on the hypothetical mixing line, as shown in Fig. 6, because the nitrate influx in winter occupied a major portion of the annual nitrate influx. Active removal of nitrate from the streams through denitrifi- 
cation/assimilation in summer was also responsible for the small relative importance of nitrate influx into the lake in summer. In conclusion, the relationship between $\Delta^{17} \mathrm{O}$ and $\delta^{18} \mathrm{O}$ of nitrate eluted from a catchment area is a useful indicator for evaluating the biogeochemical processing within the catchment area, including the seasonal change.

\subsection{Spatial and temporal $\Delta^{17} \mathrm{O}$ variation}

By using the $\delta^{18} \mathrm{O}$ values of nitrate as a tracer, Ohte et al. (2010) found that the mole fractions of unprocessed $\mathrm{NO}_{3}^{-}$(atm) within the total nitrate pool were high in the northern streams of the watershed in winter, from November to late April. Our present results shown in Fig. 5 further verify the past results by adding more robust evidence through the use of the $\Delta^{17} \mathrm{O}$ tracer for $\mathrm{NO}_{3}^{-}$(atm).

Based on the high accumulation rate of snow in the catchment zones of the northern streams, Ohte et al. (2010) concluded that high loading of unprocessed $\mathrm{NO}_{3}^{-}$(atm) via snow in the catchment zones increased the stored unprocessed $\mathrm{NO}_{3}^{-}$(atm) in the snowpack, which was subsequently released into the streams during the melting seasons. This process enhanced the mole fraction of unprocessed $\mathrm{NO}_{3}^{-}(\mathrm{atm})$ within the total nitrate pool during the melting season, as was also reported for streams worldwide (Kendall et al., 1995; Ohte et al., 2004, 2010; Piatek et al., 2005; Pellerin et al., 2012; Tsunogai et al., 2014). However, the contribution of nitrate from anthropogenic sources could be smaller in this northern area because of lower population densities in the catchments (Table 1). Because a major portion of the possible anthropogenic nitrate in the catchments must be occupied by $\mathrm{NO}_{3}^{-}$(re) (Ohte et al., 2010), a lower $\mathrm{NO}_{3}^{-}$(re) supply from anthropogenic sources in each catchment area could elevate the mole fraction of unprocessed $\mathrm{NO}_{3}^{-}(\mathrm{atm})$ within the total nitrate pool, even if the absolute concentration of $\mathrm{NO}_{3}^{-}$(atm) $\left(C_{\text {atm }}\right)$ were uniform in the streams.

To determine the $C_{\text {atm }}$ variability among the streams, the $C_{\text {atm }}$ values estimated in this study were plotted as a function of population density, as shown in Fig. 7b. The $C_{\text {atm }}$ was almost uniform at $(2.3 \pm 1.1) \mu \mathrm{mol} \mathrm{L}^{-1}$ irrespective of changes in the population density of the catchment areas. However, a clear $C_{\text {total }}$ enrichment trend was noted in accordance with increasing population density of the catchments (Fig. 7a). Similar $C_{\text {total }}$ enrichment trends have been reported in previous studies (Ohte et al., 2010).

The northern streams such as nos. 3, 4, and 5 were enriched in $C_{\text {atm }}$, showing annual average $C_{\text {atm }}$ of $(5.3 \pm 1.1)$, $(2.9 \pm 0.7)$, and $(4.3 \pm 0.9) \mu \mathrm{mol} \mathrm{L}^{-1}$ respectively and $\Delta^{17} \mathrm{O}$ values of $+3.1,+1.9$, and $+2.9 \%$ o respectively. These results support the previous observation of the streams determined by using the $\delta^{18} \mathrm{O}$ tracer. Similar $C_{\text {atm }}$ enrichment of about $3 \mu \mathrm{mol} \mathrm{L}{ }^{-1}$ or more, however, was also found in streams in other areas, such as nos. $14\left(C_{\mathrm{atm}}=(3.3 \pm 1.0) \mu \mathrm{mol} \mathrm{L}^{-1}\right)$, $25\left((3.2 \pm 0.8) \mu \mathrm{mol} \mathrm{L}^{-1}\right)$, and $21\left((4.2 \pm 0.9) \mu \mathrm{mol} \mathrm{L}^{-1}\right)$, but these streams showed lower $\Delta^{17} \mathrm{O}$ values of $+0.9,+1.5$, and
$+2.0 \%$ respectively and thus low mole fractions of unprocessed $\mathrm{NO}_{3}^{-}$(atm) within total nitrate. We concluded that the difference in the addition of anthropogenic nitrate composed of $\mathrm{NO}_{3}^{-}$(re) in the catchments was primarily responsible for the difference in the mole fraction of unprocessed $\mathrm{NO}_{3}^{-}$(atm) within the total nitrate pool, as well as the $C_{\text {total }}$ variation in accordance with the population densities of the catchment areas, as illustrated in Fig. 1. That is, a small contribution of anthropogenic nitrate in the catchments of the northern rivers was primarily responsible for the low $C_{\text {total }}$ and thus the high mole fraction of unprocessed $\mathrm{NO}_{3}^{-}(\mathrm{atm})$ within the total nitrate pool, or the $C_{\text {atm }} / C_{\text {total }}$ ratio, in the northern streams of the watershed.

Although the difference in the accumulation rate of snow between each catchment zone was not the major factor controlling the $C_{\text {atm }} / C_{\text {total }}$ ratios, the concentrated release of $\mathrm{NO}_{3}^{-}$(atm) stored in the snowpack during the melting seasons should be one of the important factors determining the $C_{\text {atm }}$ variation among the streams. Most of the $C_{\mathrm{atm}}-$ enriched streams, such as nos. 3, 4, 5, 14, and 25, originated from a forested catchment at a high elevation of more than $800 \mathrm{~m}$ above sea level; thus, we can anticipate heavy snowpack in winter in each headwater region. Moreover, the maximum $C_{\text {atm }}$ values in these streams were found in March, which is the season of snowmelt (Fig. 5). On the contrary, most of the $C_{\mathrm{atm}}$-depleted streams, such as nos. $29\left((0.9 \pm 0.3) \mu \mathrm{mol} \mathrm{L}{ }^{-1}\right), 19\left((0.8 \pm 0.3) \mu \mathrm{mol} \mathrm{L}^{-1}\right), 23$ $\left((0.5 \pm 0.2) \mu \mathrm{mol} \mathrm{L}^{-1}\right)$, and $30\left((0.6 \pm 0.2) \mu \mathrm{mol} \mathrm{L}^{-1}\right)$, originated from low elevations with urban and suburban catchment areas (Table 1). As a result, the concentrated release of stored $\mathrm{NO}_{3}^{-}(\mathrm{atm})$ in the snowpack to the forest floor in the catchment zone during the melting seasons is strongly responsible for the $C_{\text {atm }}$ enrichment of some of the streams, particularly that in the streams during the month of March, as presented in Fig. 1.

The only exception is stream no. 21 , located in the southernmost part of the watershed, which showed a high annual average $C_{\text {atm }}$ of $(4.2 \pm 0.9) \mu \mathrm{mol} \mathrm{L}^{-1}$. This small stream originates from a low elevation of about $200 \mathrm{~m}$ and has a small catchment area of $4 \mathrm{~km}^{2}$. In addition, although the other $C_{\text {atm }}$-enriched streams showed the maximum $C_{\text {atm }}$ in March, $C_{\text {atm }}$ in stream no. 21 was highest in August, showing an extraordinarily high value of more than $10 \mu \mathrm{mol} \mathrm{L}{ }^{-1}$. It is unlikely that $\mathrm{NO}_{3}^{-}(\mathrm{atm})$ stored in the snowpack in winter was the major source of $\mathrm{NO}_{3}^{-}$(atm) in this stream.

The catchment zone of stream no. 21 had the highest population density of the catchments of the streams studied (Table 1). About one-third of the catchment includes residential areas. Artificial drainage systems in urban or residential areas and agricultural lands in humid temperate regions are usually designed to drain rainwater efficiently into streams (Takimoto et al., 1994). As a result, a significant portion of the $\mathrm{NO}_{3}^{-}$(atm) deposited into the catchment area was deposited onto paved surfaces and was then drained directly 
into the stream via storm sewers without penetrating the ground. Thus, no interaction with soils occurred, as presented in Fig. 1. Because biogeochemical interactions within soils are the major sink for $\mathrm{NO}_{3}^{-}(\mathrm{atm})$ and thus for ${ }^{17} \mathrm{O}$ excess of nitrate (Nakagawa et al., 2013; Tsunogai et al., 2014), the development of such drainage systems in urban/suburban areas is largely responsible for the high $C_{\text {atm }}$ in stream no. 21 . Similar bypassing effects of $\mathrm{NO}_{3}^{-}(\mathrm{atm})$ from soil contact by paved surfaces have been suggested in urban/suburban watersheds by using $\delta^{18} \mathrm{O}$ values of nitrate as a tracer (Burns et al., 2009; Kaushal et al., 2011). We further verified that the drainage systems in urban/suburban catchments changed the fate of the $\mathrm{NO}_{3}^{-}(\mathrm{atm})$ deposited onto land to some extent.

The observed uniform $C_{\text {atm }}$ irrespective of population density and headwater elevation shown in Fig. 7 implies that the influences of snowpacks and paved surfaces were still minor in determining the $C_{\text {atm }}$ values in the streams. Rather, the observed stable $C_{\text {atm }}$ implies that most of the $\mathrm{NO}_{3}^{-}(\mathrm{atm})$ in the streams had been stored in groundwater/subsurface runoff in the watershed, which had similar $C_{\text {atm }}$ concentrations, and then gushed to the surface at the respective headwater zones with various elevations and land uses, as presented in Fig. 1.

When using the $\delta^{18} \mathrm{O}$ tracer, it was difficult to determine the precise absolute concentration of $\mathrm{NO}_{3}^{-}(\mathrm{atm})\left(C_{\mathrm{atm}}\right)$ in each stream water, as presented in this study, and to determine whether the absolute concentration of $\mathrm{NO}_{3}^{-}(\mathrm{atm})$ was stable among the streams. However, by using the $\Delta^{17} \mathrm{O}$ values, we can determine the precise $C_{\text {atm }}$ in each stream for each season and thus clarify the fate of $\mathrm{NO}_{3}^{-}(\mathrm{atm})$.

\subsection{Differences in outflows from inflows}

The concentrations and $\delta^{15} \mathrm{~N}, \delta^{18} \mathrm{O}$, and $\Delta^{17} \mathrm{O}$ values of nitrate in the outflow river (Seta River; no. 33) are also presented in Fig. 5. In a manner similar to the inflow streams (i.e. by using Eqs. 3 to 5), we estimated the annual average concentration of total nitrate in the outflow river $\left(\bar{C}_{\text {total }}\right)$ to be $13.3 \mu \mathrm{mol} \mathrm{L}{ }^{-1}$, the annual average $\delta^{15} \mathrm{~N}$ value $\left(\overline{\delta^{15} \mathrm{~N}}\right)$ to be $+13.1 \%$, the annual average $\delta^{18} \mathrm{O}$ value $\left(\overline{\delta^{18} \mathrm{O}}\right)$ to be $+1.5 \%$, and the annual average $\Delta^{17} \mathrm{O}$ value $\left(\overline{\Delta^{17} \mathrm{O}}\right)$ to be $+0.9 \%$, as presented in Fig. 5. Moreover, in a manner similar to that used for the inflow streams (i.e. by using Eqs. 2, 6, and 7), we estimated the annual average concentration of $\mathrm{NO}_{3}^{-}(\mathrm{atm})$ in the outflow river $\left(\bar{C}_{\mathrm{atm}}\right)$ to be $(0.4 \pm 0.1) \mu \mathrm{mol} \mathrm{L}^{-1}$ (Fig. 5e), the annual average $\delta^{15} \mathrm{~N}_{\mathrm{re}}$ value $\left(\bar{\delta}^{15} \mathrm{~N}_{\mathrm{re}}\right)$ to be $(+13.7 \pm 0.6) \%$, and the annual average $\delta^{18} \mathrm{O}_{\text {re }}$ value $\left(\bar{\delta}^{18} \mathrm{O}_{\text {re }}\right)$ to be $(-1.2 \pm 0.9) \%$ o (Table S5). Similar to those for inflows, the $\Delta^{17} \mathrm{O}$ values were typical for nitrate in natural stream waters.

The striking features of the outflow in comparison with the inflows were the depletions in the outflow of both $C_{\text {total }}$ and $C_{\text {atm }}$ as well as the enrichment in ${ }^{15} \mathrm{~N}$ (Fig. 5). Because the denitrification/assimilation processes remove both nitrate and $\mathrm{NO}_{3}^{-}(\mathrm{atm})$ and preferentially consume ${ }^{14} \mathrm{~N}$ during the re- moval, the process of denitrification/assimilation in the lake water column can be strongly responsible for the removal of both nitrate and $\mathrm{NO}_{3}^{-}(\mathrm{atm})$ and for the ${ }^{15} \mathrm{~N}$ enrichment of nitrate in the outflow compared with the inflow. If this were the case in Lake Biwa, the total nitrate efflux would have to be smaller than the total nitrate influx. To verify this hypothesis quantitatively and to evaluate the influences of the stagnant flow in the lake on nitrate, we estimated the total influx through all of the inflow streams for nitrate and $\mathrm{NO}_{3}^{-}(\mathrm{atm})$, $\Delta \mathrm{N}_{\mathrm{in}}$, and $\Delta \mathrm{A}_{\mathrm{in}}$ respectively and the total efflux for nitrate and $\mathrm{NO}_{3}^{-}(\mathrm{atm}), \Delta \mathrm{N}_{\text {out }}$, and $\Delta \mathrm{A}_{\text {out }}$ respectively, as well as the flow-weighted average $\delta^{15} \mathrm{~N}, \delta^{18} \mathrm{O}$, and $\Delta^{17} \mathrm{O}$ values of all inflows and outflows to discuss their changes in the lake.

The $\Delta \mathrm{N}_{\text {in }}$ and $\Delta \mathrm{A}_{\text {in }}$ in each interval between the observation $n$ and the next observation $n+1$ (i.e. each season) and the flow-weighted average $\delta^{15} \mathrm{~N}, \delta^{18} \mathrm{O}$, and $\Delta^{17} \mathrm{O}$ values of the inflows $(\delta(n))$ during each interval between the observation $n$ and the next observation $n+1$ were determined by using the following equations, assuming the same flow rate, the same nitrate concentration, and the same isotopic compositions for the interval until the next observation:

$$
\begin{aligned}
\alpha & =\frac{Q_{\text {in }}}{\sum_{i} q_{i}}, \\
\Delta \mathrm{N}_{\text {in }}(n) & =\sum_{i} C_{i} \cdot f_{i} \cdot \Delta t_{n} \cdot \alpha, \\
\delta(n) & =\frac{\sum_{i} \delta_{i} \cdot C_{i} \cdot f_{i} \cdot \Delta t_{n}}{\sum_{i} C_{i} \cdot f_{i} \cdot \Delta t_{n}}, \\
\Delta \mathrm{A}_{\text {in }}(n) & =\Delta \mathrm{N}_{\text {in }}(n) \cdot \frac{\Delta{ }^{17} \mathrm{O}_{\text {in }}(n)}{\Delta{ }^{17} \mathrm{O}_{\mathrm{atm}}}, \\
\Delta \mathrm{N}_{\text {in }} & =\sum_{n=1}^{4} \Delta \mathrm{N}_{\text {in }}(n), \\
\Delta \mathrm{A}_{\text {in }} & =\sum_{n=1}^{4} \Delta \mathrm{A}_{\text {in }}(n), \\
\delta & =\frac{\sum_{n=1}^{4} \delta(n) \cdot \Delta \mathrm{N}_{\mathrm{in}}(n)}{\sum_{n=1}^{4} \Delta \mathrm{N}_{\text {in }}(n)},
\end{aligned}
$$

where $Q_{\text {in }}$ denotes the annual gross influx of water into the lake; $C_{i}$ and $\delta_{i}$ denote the concentration and isotopic values $\left(\delta^{15} \mathrm{~N}, \delta^{18} \mathrm{O}\right.$, or $\left.\Delta^{17} \mathrm{O}\right)$ of nitrate in each stream $i$ during each observation $n$ respectively; $f_{i}$ denotes the flow rate of each stream $i$ during each observation $n$; and $\Delta \mathrm{t}_{n}$ denotes the time interval between the observation $n$ and the next observation $n+1$.

For $Q_{\text {in }}$, we used the annual influx of water estimated by Kunimatsu (1995), in which influx via streams and via groundwater were included. To include the influx of nitrate via groundwater and the other minor streams not measured 
Table 2. Estimated gross influx/efflux of total nitrate $(\Delta \mathrm{N})$ and atmospheric nitrate $(\Delta \mathrm{A})$ via inflows/outflows during each observation interval, together with the average $\delta^{15} \mathrm{~N}, \delta^{18} \mathrm{O}$, and $\Delta^{17} \mathrm{O}$ values of total nitrate and remineralised portions of nitrate $\left(\delta^{15} \mathrm{~N}_{\mathrm{re}}\right.$ and $\left.\delta^{18} \mathrm{O}_{\mathrm{re}}\right)$ in the inflows/outflows during each interval.

\begin{tabular}{|c|c|c|c|c|c|}
\hline Duration (days) & $\begin{array}{r}\text { Spring } \\
(n=1 \text { to } 2) \\
94\end{array}$ & $\begin{array}{r}\text { Summer } \\
(n=2 \text { to } 3) \\
49\end{array}$ & $\begin{array}{r}\text { Autumn } \\
(n=3 \text { to } 4) \\
77\end{array}$ & $\begin{array}{r}\text { Winter } \\
(n=4 \text { to } 5) \\
145\end{array}$ & $\begin{array}{r}\text { Annual } \\
(n=1 \text { to } 5) \\
365\end{array}$ \\
\hline \multicolumn{6}{|l|}{ Inflow } \\
\hline$\Delta \mathrm{N}_{\text {in }}\left(10^{6} \mathrm{~mol}\right)$ & $69 \pm 14$ & $3 \pm 1$ & $13 \pm 3$ & $114 \pm 23$ & $199 \pm 40$ \\
\hline$\Delta \mathrm{A}_{\text {in }}\left(10^{6} \mathrm{~mol}\right)$ & $6.4 \pm 1.3$ & 0.1 & $0.8 \pm 0.2$ & $2.8 \pm 0.6$ & $10.1 \pm 2.0$ \\
\hline $10^{3} \times \delta^{15} \mathrm{~N}$ & +4.0 & +6.8 & +5.6 & +5.6 & +5.1 \\
\hline $10^{3} \times \delta^{18} \mathrm{O}$ & +6.1 & -0.8 & +3.3 & -1.5 & +1.4 \\
\hline $10^{3} \times \Delta^{17} \mathrm{O}$ & +2.5 & +0.8 & +1.7 & +0.6 & +1.3 \\
\hline $10^{3} \times \delta^{15} \mathrm{~N}_{\mathrm{re}}$ & $+4.8 \pm 0.7$ & $+7.1 \pm 0.2$ & $+6.3 \pm 0.5$ & $+5.9 \pm 0.2$ & $+5.6 \pm 0.3$ \\
\hline $10^{3} \times \delta^{18} \mathrm{O}_{\mathrm{re}}$ & $-1.5 \pm 1.8$ & $-3.2 \pm 0.5$ & $-2.0 \pm 1.2$ & $-3.5 \pm 0.4$ & $-2.8 \pm 0.9$ \\
\hline \multicolumn{6}{|l|}{ Outflow } \\
\hline$\Delta \mathrm{N}_{\text {out }}\left(10^{6} \mathrm{~mol}\right)$ & $24 \pm 5$ & $6 \pm 1$ & $5 \pm 1$ & $32 \pm 6$ & $67 \pm 13$ \\
\hline$\Delta \mathrm{A}_{\text {out }}\left(10^{6} \mathrm{~mol}\right)$ & $1.4 \pm 0.1$ & 0.1 & 0.2 & $0.4 \pm 0.1$ & $2.2 \pm 0.4$ \\
\hline $10^{3} \times \delta^{15} \mathrm{~N}$ & +7.3 & +11.4 & +10.4 & +18.0 & +13.1 \\
\hline $10^{3} \times \delta^{18} \mathrm{O}$ & +3.4 & +4.8 & +3.0 & -0.7 & +1.5 \\
\hline $10^{3} \times \Delta^{17} \mathrm{O}$ & +1.6 & +0.4 & +1.4 & +0.4 & +0.9 \\
\hline $10^{3} \times \delta^{15} \mathrm{~N}_{\mathrm{re}}$ & $+8.1 \pm 0.6$ & $+11.7 \pm 0.4$ & $+11.2 \pm 0.9$ & $+18.3 \pm 0.4$ & $+13.7 \pm 0.6$ \\
\hline $10^{3} \times \delta^{18} \mathrm{O}_{\mathrm{re}}$ & $-1.5 \pm 1.4$ & $+3.6 \pm 0.6$ & $-1.2 \pm 1.2$ & $-1.9 \pm 0.5$ & $-1.2 \pm 0.9$ \\
\hline
\end{tabular}

in this study in the calculations, we used the correction factor $\alpha$ in Eqs. (10) and (11), whereby we assumed that both the average concentration and average isotopic compositions of the inflows determined in this study represented those of all inflows into the lake, while assuming an error range of $20 \%$ in $\alpha$. Under the $Q_{\text {in }}$, the correction factor $\alpha$ used in this study became $1.9 \pm 0.4$.

By using the aforementioned equations, we estimated the total influx of nitrate to the lake $\left(\Delta \mathrm{N}_{\text {in }}\right)$ for each interval, together with the average $\delta^{15} \mathrm{~N}, \delta^{18} \mathrm{O}$, and $\Delta^{17} \mathrm{O}$ values of nitrate during each interval, as presented in Table 2. Moreover, by using the values of $\Delta \mathrm{N}_{\text {in }}$ during each interval, as well as their $\delta^{15} \mathrm{~N}, \delta^{18} \mathrm{O}$, and $\Delta^{17} \mathrm{O}$ values, we estimated the total influx of $\mathrm{NO}_{3}^{-}(\mathrm{atm})$ to the lake $\left(\Delta \mathrm{A}_{\text {in }}\right)$ and the average $\delta^{15} \mathrm{~N}_{\mathrm{re}}$ and $\delta^{18} \mathrm{O}_{\mathrm{re}}$ values for each interval, as presented in Table 2, by using Eqs. (13), (6), and (7). Furthermore, we estimated the annual total influx and the various annual average influx values, as shown in Table 2.

The annual average $\Delta \Delta^{17} \mathrm{O}$ value of inflows estimated by using Eq. (16) was $+1.3 \%$, which corresponds to an average mole fraction of $\mathrm{NO}_{3}^{-}(\mathrm{atm})$ within total nitrate of $(5.1 \pm 0.5) \%$ by Eq. (2). We concluded that about $5 \%$ of the total nitrate in the inflows originated directly from the atmosphere; therefore, the remainder of the nitrate had a remineralised origin $\left(\mathrm{NO}_{3}^{-}(\mathrm{re})\right)$ and was likely produced through nitrification within the catchments, as discussed in Sec. 3.4. In addition, we estimated the annual total influx of nitrate to the lake $\left(\Delta \mathrm{N}_{\text {in }}\right)$ to be $(199 \pm 40) \mathrm{Mmol}$ and that of $\mathrm{NO}_{3}^{-}(\mathrm{atm})$ $\left(\Delta \mathrm{A}_{\text {in }}\right)$ to be $(10.1 \pm 2.0) \mathrm{Mmol}$.

Moreover, we estimated the total efflux of nitrate and $\mathrm{NO}_{3}^{-}(\mathrm{atm})$ from the lake via the outflows $\left(\Delta \mathrm{N}_{\text {out }}\right.$ and $\left.\Delta \mathrm{A}_{\text {out }}\right)$ for each interval by using Eqs. (10) to (16) in which $\Delta \mathrm{N}_{\text {in }}$ was replaced with $\Delta \mathrm{N}_{\text {out }}$, and $\Delta \mathrm{A}_{\text {in }}$ was replaced with $\Delta \mathrm{A}_{\text {out }}$. Additionally, $\mathrm{Q}_{\text {in }}$ was replaced with $\mathrm{Q}_{\text {out }}$, which is the annual gross efflux of water. To include the minor effluxes of nitrate to $\Delta \mathrm{N}_{\text {out }}$, such as those via canals, we used the correction factor $\gamma$ instead of $\alpha$ in Eqs. (10) and (11), whereby we assumed that both the concentration and isotopic compositions of the natural outflow determined for each season in this study represented all outflows. For $Q_{\text {out }}$, we used the annual efflux of water from Lake Biwa estimated by Kunimatsu (1995), which included the efflux via a natural river (Seta River, no. 33) and via canals. Under the $Q_{\text {out }}$, the correction factor $\gamma$ used in this study became $1.1 \pm 0.2$.

Compared with the annual $\Delta \mathrm{N}_{\text {in }}$ and the annual $\Delta \mathrm{A}_{\text {in }}$, both the annual $\Delta \mathrm{N}_{\text {out }}$ and the annual $\Delta \mathrm{A}_{\text {out }}$ were significantly smaller by about 66 and $78 \%$ respectively. Hence, Lake Biwa acts as a net sink for both nitrate and $\mathrm{NO}_{3}^{-}(\mathrm{atm})$, as previously implied from the ${ }^{15} \mathrm{~N}$ enrichment in outflows. Considering that nitrate constituted about $70 \%$ of the total fixed $\mathrm{N}$ pool in the inflows and about $40 \%$ of the total fixed $\mathrm{N}$ pool in the outflows (Shiga Prefecture, 2015), Lake Biwa also acts as a net sink for fixed N. Similar results were obtained in previous studies that discussed the fixed $\mathrm{N}$ input/output of the lake (Tezuka, 1985, 1992; Kunimatsu, 1995; Yamada et 
al., 1996). As implied by the significant ${ }^{15} \mathrm{~N}$ enrichment in the remineralised portion of nitrate $\left(\delta^{15} \mathrm{~N}_{\mathrm{re}}\right)$ in the outflow, $(+13.7 \pm 0.6) \%$ o, compared to the inflow, $(+5.6 \pm 0.3) \%$, partial removal of nitrate through either assimilation or denitrification is strongly responsible for the $(8.1 \pm 1.1) \%$ increase in $\delta^{15} \mathrm{~N}_{\mathrm{re}}$ as well as the net removal of both nitrate and $\mathrm{NO}_{3}^{-}(\mathrm{atm})$ from the lake.

In contrast, the $\delta^{18} \mathrm{O}$ differences in the remineralised portion of nitrate $\left(\delta^{18} \mathrm{O}_{\mathrm{re}}\right)$ between the inflows and outflows were significantly smaller than those of $\delta^{15} \mathrm{~N}_{\mathrm{re}}$, at an annual average of only $(1.6 \pm 1.8) \%$ (Table 2$)$. When the nitrate in the outflows is the residual nitrate of assimilation/denitrification in the lake, $\delta^{18} \mathrm{O}_{\mathrm{re}}$ should also increase (Granger et al., 2004, 2008). The much smaller $\delta^{18} \mathrm{O}_{\text {re }}$ difference implies that nitrate supplied directly from inflows occupied a small portion of the nitrate in the outflows and that most of nitrate with high $\delta^{15} \mathrm{~N}$ values in the outflows was produced through nitrification in the lake water column in which the fixed $\mathrm{N}$ was enriched in ${ }^{15} \mathrm{~N}$. Isotopic fractionations during fixed $\mathrm{N}$ cycling in the lake, such as during denitrification or assimilation, and the subsequent removal of ${ }^{15} \mathrm{~N}$-depleted organic $\mathrm{N}$ during sedimentation (Fig. 1) are likely responsible for the ${ }^{15} \mathrm{~N}$ enrichment of the total fixed $\mathrm{N}$. That is, most of nitrate fed into the lake via the inflows was removed at least once from the lake water column and was involved in the total fixed $\mathrm{N}$ cycling in the lake, in which the ${ }^{15} \mathrm{~N}$ enriched nitrate in the outflow was produced (Fig. 1). The stagnation of flow in the lake (around 5 years) encouraged primary production and thus the net removal of total fixed $\mathrm{N}$ through either denitrification or sedimentation, which resulted in ${ }^{15} \mathrm{~N}$ enrichment of the total fixed $\mathrm{N}$ pool compared with that in the inflows. Further studies on $\mathrm{N}$ cycling in the lake are needed to verify these results.

\section{Concluding remarks}

In this study, we applied the $\Delta^{17} \mathrm{O}$ tracer of nitrate to determine accurate and precise mole fractions of unprocessed $\mathrm{NO}_{3}^{-}(\mathrm{atm})$ within the total nitrate value for more than 30 streams in the Lake Biwa watershed basin. Although the nitrate concentration varied from 12.7 to $106.2 \mu \mathrm{mol} \mathrm{L}^{-1}$ among the inflow streams and the mole fraction of $\mathrm{NO}_{3}^{-}(\mathrm{atm})$ within the total nitrate also varied from 1.8 to $11.8 \%$, the absolute concentration of $\mathrm{NO}_{3}^{-}(\mathrm{atm})\left(C_{\mathrm{atm}}\right)$ in each stream water was almost stable at $(2.3 \pm 1.1) \mu \mathrm{mol} \mathrm{L}^{-1}$ irrespective of the changes in population density and land use among the catchment areas. We concluded that changes in population density and land use among the catchment areas had little impact on $C_{\text {atm }}$ and that the total nitrate concentration was determined primarily by the extent of the additional $\mathrm{NO}_{3}^{-}(\mathrm{re})$ contribution, which was mostly from anthropogenic sources. When relying on only the $\delta^{15} \mathrm{~N}$ and $\delta^{18} \mathrm{O}$ tracers of nitrate, it was difficult to determine the precise $C_{\text {atm }}$ in the stream water and whether $C_{\text {atm }}$ was uniform among the streams. By using the $\Delta^{17} \mathrm{O}$ values, we were able to estimate accurate and precise $C_{\text {atm }}$ in each stream for each season; thus, we could clarify the fate of the $\mathrm{NO}_{3}^{-}(\mathrm{atm})$ deposited into the catchments.

Moreover, additional measurements of the $\Delta^{17} \mathrm{O}$ values of nitrate together with $\delta^{15} \mathrm{~N}$ and $\delta^{18} \mathrm{O}$ enabled us to exclude the contribution of $\mathrm{NO}_{3}^{-}(\mathrm{atm})$ from the determined $\delta^{15} \mathrm{~N}$ and $\delta^{18} \mathrm{O}$ values and to use the corrected $\delta^{15} \mathrm{~N}$ and $\delta^{18} \mathrm{O}$ values, $\delta^{15} \mathrm{~N}_{\mathrm{re}}$ and $\delta^{18} \mathrm{O}_{\mathrm{re}}$, to evaluate the source and behaviour of $\mathrm{NO}_{3}^{-}(\mathrm{re})$ in each stream. Based on the correction, we successfully estimated the $\delta^{15} \mathrm{~N}$ and $\delta^{18} \mathrm{O}$ values of $\mathrm{NO}_{3}^{-}$(re) in the streams to be $(+4.4 \pm 1.8) \%$ and $(-2.3 \pm 0.9) \%$ respectively for $\mathrm{NO}_{3}^{-}$produced through nitrification in naturally occurring soil organic matter and $(+9.2 \pm 1.3) \%$ and $(-2.2 \pm 1.1) \%$ respectively for $\mathrm{NO}_{3}^{-}$supplied from anthropogenic sources, most of which were sewage effluent. In addition, the low and uniform annual average $\delta^{18} \mathrm{O}_{\mathrm{re}}$ values of $\mathrm{NO}_{3}^{-}(\mathrm{re})$ in the streams implied that denitrification in the riverbed sediments was minor in the streams.

Furthermore, we clarified the seasonal changes in the range of isotopic fractionation through partial nitrate removal via assimilation or denitrification by using the relationship between $\Delta^{17} \mathrm{O}$ and $\delta^{18} \mathrm{O}$ of nitrate in the streams. The changes were small in winter in all of the catchment areas but large in summer in some catchments. Therefore, the relationship between $\Delta^{17} \mathrm{O}$ and $\delta^{18} \mathrm{O}$ of nitrate eluted from a catchment area is a powerful indicator for evaluating the biogeochemical nitrogen cycles within a catchment area, including the seasonal changes.

Based on the annual influx and efflux of both nitrate and $\mathrm{NO}_{3}^{-}(\mathrm{atm})$ in Lake Biwa newly estimated in this study, we found that Lake Biwa is a net sink for both nitrate and $\mathrm{NO}_{3}^{-}(\mathrm{atm})$. Additionally, we found significant ${ }^{15} \mathrm{~N}$ enrichment $((+8.1 \pm 1.1) \% o)$ in the remineralised portion of nitrate in the outflow compared with those in the inflows, whereas the ${ }^{18} \mathrm{O}$ enrichment was only $(+1.6 \pm 1.8) \%$. We concluded that most of the nitrate fed into the lake via the inflows was removed at least once from the lake water column and was involved in the total fixed $\mathrm{N}$ cycling in the lake, by which the ${ }^{15} \mathrm{~N}$-enriched nitrate in the outflow was produced (Fig. 1). The stagnation of flow in the lake encouraged primary production and thus net removal of total fixed $\mathrm{N}$ through either denitrification or sedimentation, which resulted in ${ }^{15} \mathrm{~N}$ enrichment of the total fixed $\mathrm{N}$ pool compared with that of the inflows.

\section{The Supplement related to this article is available online at doi:10.5194/bg-13-3441-2016-supplement.}


Acknowledgements. We are grateful to Kosuke Ikeya, Hiroki Sakuma, Sho Minami, Kenta Ando, Shuichi Hara, Toshiyuki Matsushita, Takahiro Mihara, Teresa Fukuda, Yoshiumi Matsumoto, Rei Nakane, Lin Cheng, Yuuko Nakano, and other present and past members of the Biogeochemistry Group, Nagoya University, for their valuable support throughout this study. We thank Shin-ichi Nakano, Tadatoshi Koitatabashi, Yukiko Goda, and other staff of the Center for Ecological Research, Kyoto University, for their valuable support during the field study in the Lake Biwa watershed basin. We also thank the members of the Machine Shop of Nagoya University Technical Center for their valuable support in developing the sampling and analytical devices used in this study. We thank anonymous reviewers for valuable remarks on an earlier version of the manuscript. This work was supported by a grant-in-aid for scientific research from the Ministry of Education, Culture, Sports, Science, and Technology of Japan under grant numbers 24651002, 26241006, and 15H02804.

Edited by: R. Bol

\section{References}

Alexander, B., Hastings, M. G., Allman, D. J., Dachs, J., Thornton, J. A., and Kunasek, S. A.: Quantifying atmospheric nitrate formation pathways based on a global model of the oxygen isotopic composition $\left(\Delta^{17} \mathrm{O}\right)$ of atmospheric nitrate, Atmos. Chem. Phys., 9, 5043-5056, doi:10.5194/acp-9-5043-2009, 2009.

Aravena, R., Evans, M. L., and Cherry, J. A.: Stable Isotopes of Oxygen and Nitrogen in Source Identification of Nitrate from Septic Systems, Groundwater, 31, 180-186, 1993.

Barnes, R. and Raymond, P. A.: Land-use controls on sources and processing of nitrate in small watersheds: insights from dual isotopic analysis, Ecol. Appl., 20, 1961-1978, 2010.

Barnes, R., Raymond, P., and Casciotti, K.: Dual isotope analyses indicate efficient processing of atmospheric nitrate by forested watersheds in the northeastern US, Biogeochemistry, 90, 15-27, 2008.

Böttcher, J., Strebel, O., Voerkelius, S., and Schmidt, H. L.: Using Isotope Fractionation of Nitrate Nitrogen and Nitrate Oxygen for Evaluation of Microbial Denitrification in a Sandy Aquifer, J. Hydrol., 114, 413-424, 1990.

Buchwald, C., Santoro, A. E., McIlvin, M. R., and Casciotti, K. L.: Oxygen isotopic composition of nitrate and nitrite produced by nitrifying cocultures and natural marine assemblages, Limnol. Oceanogr., 57, 1361-1375, 2012.

Burns, D. A. and Kendall, C.: Analysis of $\delta^{15} \mathrm{~N}$ and $\delta^{18} \mathrm{O}$ sources in runoff at two watersheds in the Catskill Mountains of New York, Water Resour. Res., 38, 1051, doi:10.1029/2001WR000292, 2002.

Burns, D. A., Boyer, E. W., Elliott, E. M., and Kendall, C.: Sources and transformations of nitrate from streams draining varying land uses: Evidence from dual isotope analysis, J. Environ. Qual., 38, 1149-1159, 2009.

Campbell, D. H., Kendall, C., Chang, C. C. Y., Silva, S. R., and Tonnessen, K. A.: Pathways for nitrate release from an alpine watershed: Determination using $\delta^{15} \mathrm{~N}$ and $\delta^{18} \mathrm{O}$, Water Resour. Res., 38, 1052, doi:10.1029/2001WR000294, 2002.
Campbell, J. L., Mitchell, M. J., and Mayer, B.: Isotopic assessment of $\mathrm{NO}_{3}^{-}$and $\mathrm{SO}_{a}^{2-}$ mobility during winter in two adjacent watersheds in the Adirondack Mountains, New York, J. Geophys. Res. 111, G04007, doi:10.01029/02006JG000208, 2006.

Costa, A. W., Michalski, G., Schauer, A. J., Alexander, B., Steig, E. J., and Shepson, P. B.: Analysis of atmospheric inputs of nitrate to a temperate forest ecosystem from $\Delta^{17} \mathrm{O}$ isotope ratio measurements, Geophys. Res. Lett., 38, L15805, doi:10.1029/2011GL047539, 2011.

Dejwakh, N. R., Meixner, T., Michalski, G., and McIntosh, J.: Using ${ }^{17} \mathrm{O}$ to investigate nitrate sources and sinks in a semi-arid groundwater system, Environ. Sci. Technol., 46, 745-751, 2012.

Durka, W., Schulze, E.-D., Gebauer, G., and Voerkeliust, S.: Effects of forest decline on uptake and leaching of deposited nitrate determined from ${ }^{15} \mathrm{~N}$ and ${ }^{18} \mathrm{O}$ measurements, Nature, 372, 765767, 1994.

EANET: Data Report 2013, Network center for EANET (Acid Deposition Monitoring Network in East Asia), Nigata, Japan, 2014

Fang, Y., Koba, K., Makabe, A., Zhu, F., Fan, S., Liu, X., and Yoh, M.: Low delta O-18 Values of Nitrate Produced from Nitrification in Temperate Forest Soils, Environ. Sci. Technol., 46, 87238730, 2012.

Granger, J., Sigman, D. M., Needoba, J. A., and Harrison, P. J.: Coupled nitrogen and oxygen isotope fractionation of nitrate during assimilation by cultures of marine phytoplankton, Limnol. Oceanogr., 49, 1763-1773, 2004.

Granger, J., Sigman, D. M., Lehmann, M. F., and Tortell, P. D.: Nitrogen and oxygen isotope fractionation during dissimilatory nitrate reduction by denitrifying bacteria, Limnol. Oceanogr., 53, 2533-2545, 2008

Granger, J., Sigman, D. M., Rohde, M. M., Maldonado, M. T., and Tortell, P. D.: N and $\mathrm{O}$ isotope effects during nitrate assimilation by unicellular prokaryotic and eukaryotic plankton cultures, Geochim. Cosmochim. Ac., 74, 1030-1040, 2010.

Hales, H. C., Ross, D. S., and Lini, A.: Isotopic signature of nitrate in two contrasting watersheds of Brush Brook, Vermont, USA, Biogeochemistry, 84, 51-66, 2007.

Hirota, A., Tsunogai, U., Komatsu, D. D., and Nakagawa, F.: Simultaneous determination of $\delta^{15} \mathrm{~N}$ and $\delta^{18} \mathrm{O}$ of $\mathrm{N}_{2} \mathrm{O}$ and $\delta^{13} \mathrm{C}$ of $\mathrm{CH}_{4}$ in nanomolar quantities from a single water sample, Rapid Commun. Mass Spectrom., 24, 1085-1092, 2010.

Hsieh, C. H., Sakai, Y., Ban, S., Ishikawa, K., Ishikawa, T., Ichise, S., Yamamura, N., and Kumagai, M.: Eutrophication and warming effects on long-term variation of zooplankton in Lake Biwa, Biogeosciences, 8, 1383-1399, doi:10.5194/bg-8-13832011, 2011.

Johannsen, A., Dähnke, K., and Emeis, K.: Isotopic composition of nitrate in five German rivers discharging into the North Sea, Org. Geochem., 39, 1678-1689, 2008.

Kabeya, N., Katsuyama, M., Kawasaki, M., Ohte, N., and Sugimoto, A.: Estimation of mean residence times of subsurface waters using seasonal variation in deuterium excess in a small headwater catchment in Japan, Hydrol. Process., 21, 308-322, 2007.

Kaiser, J., Hastings, M. G., Houlton, B. Z., Röckmann, T., and Sigman, D. M.: Triple oxygen isotope analysis of nitrate using the denitrifier method and thermal decomposition of $\mathrm{N}_{2} \mathrm{O}$, Anal. Chem., 79, 599-607, 2007.

Kaushal, S. S., Groffman, P. M., Band, L. E., Elliott, E. M., Shields, C. A., and Kendall, C.: Tracking nonpoint source nitrogen pollu- 
tion in human-impacted watersheds, Environ. Sci. Technol., 45, 8225-8232, 2011.

Kendall, C.: Tracing Nitrogen Sources and Cycling in Catchments, in: Isotope Tracers in Catchment Hydrology, edited by: Kendall, C. and McDonnell, J. J., Elsevier Science B.V., Amsterdam, 839 pp., Amsterdam, 1998.

Kendall, C., Campbell, D. H., Burns, D. A., Schanley, J. B., Silva, S. R., and Chang, C. C. Y.: Tracing sources of nitrate in snowmelt runoff using the oxygen and nitrogen isotopic compositions of nitrate, in: Biogeochemistry of seasonally snow-covered catchments, Proceedings of a Boulder Symposium, IAHS Publication, 1995.

Komatsu, D. D., Ishimura, T., Nakagawa, F., and Tsunogai, U.: Determination of the ${ }^{15} \mathrm{~N} /{ }^{14} \mathrm{~N},{ }^{17} \mathrm{O} /{ }^{16} \mathrm{O}$, and ${ }^{18} \mathrm{O} /{ }^{16} \mathrm{O}$ ratios of nitrous oxide by using continuous-flow isotope-ratio mass spectrometry, Rapid Commun. Mass Spectrom., 22, 1587-1596, 2008.

Konno, U., Tsunogai, U., Komatsu, D. D., Daita, S., Nakagawa, F., Tsuda, A., Matsui, T., Eum, Y.-J., and Suzuki, K.: Determination of total $\mathrm{N}_{2}$ fixation rates in the ocean taking into account both the particulate and filtrate fractions, Biogeosciences, 7, 2369-2377, doi:10.5194/bg-7-2369-2010, 2010.

Kunasek, S. A., Alexander, B., Steig, E. J., Hastings, M. G., Gleason, D. J., and Jarvis, J. C.: Measurements and modeling of $\Delta^{17} \mathrm{O}$ of nitrate in snowpits from Summit, Greenland, J. Geophys. Res., 113, D24302, doi:10.1029/2008jd010103, 2008.

Kunimatsu, T.: Mass balance of Lake Biwa, LBRI bulletin, 12, 6873, 1995 (in Japanese).

Likens, G. E., Bormann, F. H., Johnson, N. M., Fisher, D. W., and Pierce, R. S.: Effects of forest cutting and herbicide treatment on nutrient budgets in the Hubbard Brook watershed-ecosystem, Ecol. Monogr., 40, 23-47, 1970.

Liu, T., Wang, F., Michalski, G., Xia, X., and Liu, S.: Using N15, O-17, and O-18 To Determine Nitrate Sources in the Yellow River, China, Enviro. Sci. Technol., 47, 13412-13421, 2013.

Lohse, K. A., Sanderman, J., and Amundson, R.: Identifying sources and processes influencing nitrogen export to a small stream using dual isotopes of nitrate, Water Resour. Res., 49, 5715-5731, 2013.

Mayer, B., Bollwerk, S. M., Mansfeldt, T., Huter, B., and Veizer, J.: The oxygen isotope composition of nitrate generated by nitrification in acid forest floors, Geochim. Cosmochim. Ac., 65, 2743-2756, 2001.

Mayer, B., Boyer, E. W., Goodale, C., Jaworski, N. A., Van Breemen, N., Howarth, R. W., Seitzinger, S., Billen, G., Lajtha, L. J., Nosal, M., and Paustian, K.: Sources of nitrate in rivers draining sixteen watersheds in the northeastern US: Isotopic constraints, Biogeochemistry, 57, 171-197, 2002.

McIlvin, M. R. and Altabet, M. A.: Chemical conversion of nitrate and nitrite to nitrous oxide for nitrogen and oxygen isotope analysis in freshwater and seawater, Anal. Chem., 77, 5589-5595, 2005.

McIsaac, G. F., David, M. B., Gertner, G. Z., and Goolsby, D. A.: Eutrophication: Nitrate flux in the Mississippi River, Nature, 414, 166-167, 2001.

McMahon, P. B. and Böhlke, J. K.: Denitrification and mixing in a stream-aquifer system: Effects on nitrate loading to surface water, J. Hydrol., 186, 105-128, 1996.
Michalski, G., Savarino, J., Böhlke, J. K., and Thiemens, M.: Determination of the total oxygen isotopic composition of nitrate and the calibration of a $\Delta^{17} \mathrm{O}$ nitrate reference material, Anal. Chem., 74, 4989-4993, 2002.

Michalski, G., Scott, Z., Kabiling, M., and Thiemens, M. H.: First measurements and modeling of $\Delta^{17} \mathrm{O}$ in atmospheric nitrate, Geophys. Res. Lett., 30, 1870, doi:10.1029/2003GL017015, 2003.

Michalski, G., Meixner, T., Fenn, M., Hernandez, L., Sirulnik, A., Allen, E., and Thiemens, M.: Tracing Atmospheric Nitrate Deposition in a Complex Semiarid Ecosystem Using $\Delta^{17} \mathrm{O}$, Environ. Sci. Technol., 38, 2175-2181, 2004.

Miller, M. F.: Isotopic fractionation and the quantification of ${ }^{17} \mathrm{O}$ anomalies in the oxygen three-isotope system: an appraisal and geochemical significance, Geochim. Cosmochim. Ac., 66, 18811889, 2002.

Morin, S., Savarino, J., Frey, M. M., Yan, N., Bekki, S., Bottenheim, J. W., and Martins, J. M. F.: Tracing the origin and fate of $\mathrm{NO}_{X}$ in the Arctic atmosphere using stable isotopes in nitrate, Science, 322, 730-732, 2008.

Morin, S., Savarino, J., Frey, M. M., Domine, F., Jacobi, H. W., Kaleschke, L., and Martins, J. M. F.: Comprehensive isotopic composition of atmospheric nitrate in the Atlantic Ocean boundary layer from $65^{\circ} \mathrm{S}$ to $79^{\circ} \mathrm{N}$, J. Geophys. Res., 114, D05303, doi:10.1029/2008jd010696, 2009.

Morin, S., Erbland, J., Savarino, J., Domine, F., Bock, J., Friess, U., Jacobi, H.-W., Sihler, H., and Martins, J. M. F.: An isotopic view on the connection between photolytic emissions of $\mathrm{NO}_{X}$ from the Arctic snowpack and its oxidation by reactive halogens, J. Geophys. Res., 117, D00R08, doi:10.1029/2011JD016618, 2012.

Nakagawa, F., Suzuki, A., Daita, S., Ohyama, T., Komatsu, D. D., and Tsunogai, U.: Tracing atmospheric nitrate in groundwater using triple oxygen isotopes: evaluation based on bottled drinking water, Biogeosciences, 10, 3547-3558, doi:10.5194/bg-10-35472013, 2013.

Nestler, A., Berglund, M., Accoe, F., Duta, S., Xue, D., Boeckx, P., and Taylor, P.: Isotopes for improved management of nitrate pollution in aqueous resources: review of surface water field studies, Environ.Sci. Pollut. Res., 18, 519-533, 2011.

Ohte, N., Sebestyen, S. D., Shanley, J. B., Doctor, D. H., Kendall, C., Wankel, S. D., and Boyer, E. W.: Tracing sources of nitrate in snowmelt runoff using a high-resolution isotopic technique, Geophys. Res. Lett., 31, L21506, doi:10.1029/2004GL020908, 2004.

Ohte, N., Tayasu, I., Kohzu, A., Yoshimizu, C., Osaka, K., Makabe, A., Koba, K., Yoshida, N., and Nagata, T.: Spatial distribution of nitrate sources of rivers in the Lake Biwa watershed, Japan: Controlling factors revealed by nitrogen and oxygen isotope values, Water Resour. Res., 46, W07505, doi:10.1029/2009wr007871, 2010.

Paerl, H. W.: Controlling eutrophication along the freshwatermarine continuum: Dual nutrient $(\mathrm{N}$ and $\mathrm{P})$ reductions are essential, Estuar. Coast., 32, 593-601, 2009.

Pellerin, B., Saraceno, J., Shanley, J., Sebestyen, S., Aiken, G., Wollheim, W., and Bergamaschi, B.: Taking the pulse of snowmelt: in situ sensors reveal seasonal, event and diurnal patterns of nitrate and dissolved organic matter variability in an upland forest stream, Biogeochemistry, 108, 183-.198, 2012. 
Piatek, K. B., Mitchell, M. J., Silva, S. R., and Kendall, C.: Sources of nitrate in snowmelt discharge: evidence from water chemistry and stable isotopes of nitrate, Water Air Soil Poll., 165, 13-35, 2005.

Riha, K. M., Michalski, G., Gallo, E. L., Lohse, K. A., Brooks, P. D., and Meixner, T.: High Atmospheric Nitrate Inputs and Nitrogen Turnover in Semi-arid Urban Catchments, Ecosystems, 17, 1309-1325, 2014.

Rose, L. A., Elliott, E. M., and Adams, M. B.: Triple Nitrate Isotopes Indicate Differing Nitrate Source Contributions to Streams Across a Nitrogen Saturation Gradient, Ecosystems, 18, 12091223, 2015.

Savarino, J., Morin, S., Erbland, J., Grannec, F., Patey, M. D., Vicars, W., Alexander, B., and Achterberg, E. P.: Isotopic composition of atmospheric nitrate in a tropical marine boundary layer, P. Natl. Acad. Sci. USA, 110, 17668-17673, 2013.

Shiga Prefecture: Annual Report on the Environment in Shiga (FY 2013), Appendix, Shiga prefecture, Ohtsu, 2015 (in Japanese).

Silva, S. R., Ging, P. B., Lee, R. W., Ebbert, J. C., Tesoriero, A. J., and Inkpen, E. L.: Forensic Applications of Nitrogen and Oxygen Isotopes in Tracing Nitrate Sources in Urban Environments, Environ. Forensics, 3, 125-130, 2002.

Spoelstra, J., Schiff, S. L., Hazlett, P. W., Jeffries, D. S., and Semkin, R. G.: The isotopic composition of nitrate produced from nitrification in a hardwood forest floor, Geochim. Cosmochim. Ac., 71, 3757-3771, 2007.

Swank, W. T., Vose, J. M., and Elliott, K. J.: Long-term hydrologic and water quality responses following commercial clearcutting of mixed hardwoods on a southern Appalachian catchment, Forest Ecol. Manag., 143, 163-178, 2001.

Takimoto, H., Tanaka, T., and Horino, H.: Does forest conserve runoff discharge during drought?, Trans. Jpn. Soc. Irrig. Drain. Reclam. Eng., 170, 75-81, 1994.

Tezuka, Y.: C:N : P Ratios of Seston in Lake Biwa as Indicators of Nutrient Deficiency in Phytoplankton and Decomposition Process of Hypolimnetic Particulate Matter, Jap. J. Limnol., 46, 239-246, 1985.

Tezuka, Y.: Recent Trend in the Eutrophication of the North Basin of Lake Biwa, Jap. J. Limnol., 53, 139-144, 1992.

Thibodeau, B., Hélie, J.-F., and Lehmann, M. F.: Variations of the nitrate isotopic composition in the St. Lawrence River caused by seasonal changes in atmospheric nitrogen inputs, Biogeochemistry, 115, 287-298, 2013

Tobari, Y., Koba, K., Fukushima, K., Tokuchi, N., Ohte, N., Tateno, R., Toyoda, S., Yoshioka, T., and Yoshida, N.: Contribution of atmospheric nitrate to stream-water nitrate in Japanese coniferous forests revealed by the oxygen isotope ratio of nitrate, Rapid Commun. Mass Spectrom., 24, 1281-1286, 2010.
Tsunogai, U., Kido, T., Hirota, A., Ohkubo, S. B., Komatsu, D. D., and Nakagawa, F.: Sensitive determinations of stable nitrogen isotopic composition of organic nitrogen through chemical conversion into $\mathrm{N}_{2} \mathrm{O}$, Rapid Commun. Mass Spectrom., 22, 345354, 2008.

Tsunogai, U., Komatsu, D. D., Daita, S., Kazemi, G. A., Nakagawa, F., Noguchi, I., and Zhang, J.: Tracing the fate of atmospheric nitrate deposited onto a forest ecosystem in Eastern Asia using $\Delta^{17}$ O, Atmos. Chem. Phys., 10, 1809-1820, doi:10.5194/acp10-1809-2010, 2010.

Tsunogai, U., Daita, S., Komatsu, D. D., Nakagawa, F., and Tanaka, A.: Quantifying nitrate dynamics in an oligotrophic lake using $\Delta^{17} \mathrm{O}$, Biogeosciences, 8, 687-702, doi:10.5194/bg-8-687-2011, 2011.

Tsunogai, U., Komatsu, D. D., Ohyama, T., Suzuki, A., Nakagawa, F., Noguchi, I., Takagi, K., Nomura, M., Fukuzawa, K., and Shibata, H.: Quantifying the effects of clear-cutting and strip-cutting on nitrate dynamics in a forested watershed using triple oxygen isotopes as tracers, Biogeosciences, 11, 54115424, doi:10.5194/bg-11-5411-2014, 2014.

Wankel, S. D., Kendall, C., Francis, C. A., and Paytan, A.: Nitrogen sources and cycling in the San Francisco Bay Estuary: A nitrate dual isotopic composition approach, Limnol. Oceanogr., 51, 1654-1664, 2006.

Widory, D., Petelet-Giraud, E., Négrel, P., and Ladouche, B.: Tracking the Sources of Nitrate in Groundwater Using Coupled Nitrogen and Boron Isotopes:? A Synthesis, Environ. Sci. Technol., 39, 539-548, 2005.

Williard, K. W. J., DeWalle, D. R., Edwards, P. J., and Sharpe, W. E.: ${ }^{18} \mathrm{O}$ isotopic separation of stream nitrate sources in mid-Appalachian forested watersheds, J. Hydrol., 252, 174-188, 2001.

Xue, D. M., Botte, J., De Baets, B., Accoe, F., Nestler, A., Taylor, P., Van Cleemput, O., Berglund, M., and Boeckx, P.: Present limitations and future prospects of stable isotope methods for nitrate source identification in surface- and groundwater, Water Res., 43, 1159-1170, 2009.

Yamada, Y., Ueda, T., and Wada, E.: Distribution of Carbon and Nitrogen Isotope Ratios in the Yodo River Watershed, Jap. J. Limnol., 57, 467-477, 1996.

Yamazaki, A., Watanabe, T., and Tsunogai, U.: Nitrogen isotopes of organic nitrogen in reef coral skeletons as a proxy of tropical nutrient dynamics, Geophys. Res. Lett., 38, L19605, doi:10.1029/2011GL049053, 2011

Zeng, H. and Wu, J.: Tracing the Nitrate Sources of the Yili River in the Taihu LakeWatershed: A Dual Isotope Approach, Water, 7, 188-201, 2015. 